\title{
Investigation of the impact of mole-fraction on the digital benchmarking parameters as well as sensitivity in GaXIn1-XAs/GaYIn1-YSb vertical heterojunctionless tunneling field effect transistor
}

\section{Behzad Rajabi}

Rasht Branch, Islamic Azad University, Rasht, Iran

Mahdi Vadizadeh ( $\sim$ vadizadeh@gmail.com)

Department of Electrical Engineering, Abhar Branch, Islamic Azad University, Abhar, Iran https://orcid.org/0000-0001-7557-0620

\section{Research Article}

Keywords: Junctionless Tunnel FET, mole fraction, tunneling effective mass, sensitivity analysis

Posted Date: March 30th, 2021

DOl: https://doi.org/10.21203/rs.3.rs-254477/v1

License: (c) (1) This work is licensed under a Creative Commons Attribution 4.0 International License.

Read Full License 


\title{
Investigation of the impact of mole-fraction on the digital benchmarking

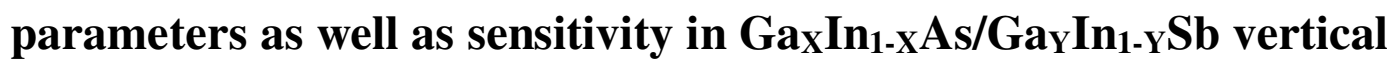 heterojunctionless tunneling field effect transistor
}

\author{
Behzad Rajabi ${ }^{\text {a }}$, Mahdi Vadizadeh ${ }^{\text {b* }}$ \\ a) Department of Electrical Engineering, Rasht Branch, Islamic Azad University, Rasht, Iran \\ $\left.b^{*}\right)$ Department of Electrical Engineering, Abhar Branch, Islamic Azad University, Abhar, Iran
}

\begin{abstract}
$\mathrm{Ga}_{X} \mathrm{In}_{1-\mathrm{X}} \mathrm{As} / \mathrm{Ga}_{Y} \mathrm{In}_{1-\mathrm{Y}} \mathrm{Sb}$ vertical heterojunctionless tunneling field effect transistor (VHJL-TFET) has been suggested to optimize the digital benchmarking parameters. In the proposed VHJL-TFET with type II heterostructure (i.e. $\mathrm{X}=0.8, \mathrm{Y}=0.85$ ), slight changes in gate voltage cause switching from OFF-state to ON-state. As a result, the electrical properties of $\mathrm{Ga}_{0.8} \mathrm{In}_{0.2} \mathrm{As} / \mathrm{Ga}_{0.85} \mathrm{In}_{0.15} \mathrm{Sb}$ VHJL-TFET are excellent in the sub-threshold region. The heterostructure with III-V semiconductors in the source-channel region increases the ON-state current (ION) of the VHJL-TFET. Comparing the results of $\mathrm{Ga}_{0.8} \mathrm{In}_{0.2} \mathrm{As} / \mathrm{Ga}_{0.85} \mathrm{In}_{0.15} \mathrm{Sb}$ VHJL-TFET with the simulated devices with type I heterostructure (i.e. $\mathrm{X}=0.9, \mathrm{Y}=0.1$ ) and type III heterostructure (i.e. $\mathrm{X}=0.1, \mathrm{Y}=0.4$ ) shows the improvement by $26 \%$ and $15 \%$ in the average subthreshold slope (SS). Sensitivity analysis for VHJL-TFET with the type II heterostructure shows that the sensitivity of OFF-state current ( $\left.\mathrm{I}_{\mathrm{OFF}}\right)$ to the body thickness $\left(\mathrm{T}_{\mathrm{b}}\right)$ and doping concentration $\left(\mathrm{N}_{\mathrm{D}}\right)$ is more than the sensitivity of the other main electrical parameters. The $\mathrm{Ga}_{0.8} \mathrm{In}_{0.2} \mathrm{As} / \mathrm{Ga}_{0.85} \mathrm{In}_{0.15} \mathrm{Sb}$ VHJL-TFET with a channel length of $20 \mathrm{~nm}, \mathrm{~T}_{\mathrm{b}}=5 \mathrm{~nm}$, and $\mathrm{N}_{\mathrm{D}}=1 \times 10^{18} \mathrm{~cm}^{-3}$ showed the $\mathrm{SS}=4.4 \mathrm{mV} / \mathrm{dec}, \mathrm{I}_{\mathrm{ON}} / \mathrm{I}_{\mathrm{OFF}}=4 \mathrm{E} 14$, and $\mathrm{I}_{\mathrm{ON}}=8 \mathrm{~mA} / \mathrm{um}$. As a result, $\mathrm{Ga}_{0.8} \mathrm{In}_{0.2} \mathrm{As} / \mathrm{Ga}_{0.85} \mathrm{In}_{0.15} \mathrm{Sb}$ VHJL-TFET can be a reasonable choice for digital applications.
\end{abstract}

Keywords: Junctionless Tunnel FET; mole fraction; tunneling effective mass; sensitivity analysis.

\section{Declarations}

Funding: Not applicable

Conflict of interest: Not applicable

Availability of data and material: Not applicable

Code availability: Not applicable

Authors' contributions: Not applicable

Ethics approval: Not applicable

Consent for publication: Not applicable

Consent for publication: Not applicable

\footnotetext{
* Corresponding author E-mail Addresses: vadizadeh@gmail.com
} 
Acknowledgments: Not applicable

\section{Introduction}

Subthreshold slope (SS) of less than $60 \mathrm{mV} / \mathrm{dec}$ and low leakage current of tunneling field effect transistor (TFET), respectively, causes an increase in switching speed and causes a reduction in static power consumption in digital circuits performance [1-3]. As a result, TFET device has attracted the attention of many researchers for digital applications [4,5]. However, the ultra-sharp doping concentration gradient in the source/channel and the drain/channel junctions complicates the fabrication process of TFET device in nanometer regime [6, 7]. Recently, a junctionless TFET (JLTFET) has been proposed, in which issues caused by ultra-sharp doping concentration gradient in the source/channel and the drain/channel junctions are eliminated [6-12]. JLTFET is a heavy doped thin film semiconductor, in which the type and level of doping are unchanged throughout the device. In fact, in JLTFET device, the advantages of conventional TFET and junctionless field effect transistor are combined [7, 13].

Silicon-based JLTFET such as conventional silicon based TFET, is suffering from issues caused by low ON-state current $\left(\mathrm{I}_{\mathrm{ON}}\right)$ due to tunneling mechanism [7, 14]. The reason is that the forbidden band width is so large that it reduces the electron tunneling probability in tunneling junction $[6,11]$. With the recent progress, the low $\mathrm{I}_{\mathrm{ON}}$ problem in JLTFET has been resolved by various strategies, such as using small band gape materials [15, 16] gate engineering [17, 18]. and hetero-gate dielectric $[11,19]$. The use of III-V materials with staggered/broken bandgaps is suggested to increase ION in JLTFET [20-23]. III-V materials have improved the performance of the JLTFET device, due to high mobility as well as lower band gap [22, 24]. JLTFET device with hetero structure is called HJLTFET. In previous works, HJL-TFET structures are presented horizontally [20-23]. It is very complex to create horizontal heterojunction structures in HJL-TFET device. Use of vertical heterojunction in HJL-TFET is feasible and can reduce the chip consumption level in integrated circuits [25].

In this paper, a vertical heterojunctionless tunneling field effect transistor with III-V materials is proposed, which is called VHJL-TFET. GaX $\mathrm{In}_{1-\mathrm{X}} \mathrm{As}$ and $\mathrm{Ga}_{\mathrm{Y}} \mathrm{In}_{1-\mathrm{Y}} \mathrm{Sb}$ are recommended as a drain-channel material and as the source material, respectively in the proposed structure. The main goal of this study is to optimize the digital benchmarking parameters of GaxIn $I_{-X} A s / G a Y I n_{1-Y} S b$ VHJL-TFET in terms of the $\mathrm{I}_{\mathrm{ON}} / \mathrm{I}_{\mathrm{OFF}}$ ratio and SS by varying the mole fraction of $\mathrm{X}$ and $\mathrm{Y}$.

The simulation results in the OFF-state show that, with changes in $\mathrm{X}$ and $\mathrm{Y}$ parameters, the type I, type II and type III hetero structures are formed in the source/channel interface. By choosing $\mathrm{X}=0.8$ and $\mathrm{Y}=0.85$ in the proposed VHJL-TFET device, the type II hetero structure is formed. As a result, with slight changes in gate voltage, the electron tunneling will occur from source valence band to channel conduction band, which can effectively improve the SS and $\mathrm{I}_{\mathrm{ON}}$. Our simulation results show that selecting a material with larger band gap in the drain-channel region as well as a material with smaller band gap in the source region in VHJL-TFET device drastically reduce the ambipolarity behavior. Based on the simulation results, the improvement of the SS and ON-state current to OFFstate current $\left(\mathrm{I}_{\mathrm{ON}} / \mathrm{I}_{\mathrm{OFF}}\right)$ ratio of VHJL-TFET structure with $\mathrm{Y}=0.85$ and $\mathrm{X}=0.8$ is noticeable compared to the recently proposed structures $[11,12,18,21,22,26]$. With changes in $\mathrm{X}$ and $\mathrm{Y}$, in addition to energy band gap and electron affinity, the electron tunneling effective mass and hole tunneling effective mass are also changed [27]. We considered these changes in our simulations. In the VHJL-TFET structure with $\mathrm{Y}=0.85$ and $\mathrm{X}=0.8$, the effect of changes in structural parameters, such as doping concentration, body thickness, and spacer width between the auxiliary gate and control gate, is investigated on the main electrical parameters. Finally, the performance of the proposed VHJL-TFET device is compared with that of the recently proposed devices.

This article is organized in 4 Sections. The structure of the device and the simulation models are described in Section 2. In Section 3, the simulation results of the VHJL-TFET structure are presented. Finally, the conclusion is provided in Section 4. 


\section{Device structure and simulation setup}

Figure 1 shows the structure of the simulated VHJL-TFET device in this paper. In the simulated structure to increase gate control over the channel, double gate technology is used. In the VHJL-TFET structure shown in Fig. 1, the source, channel, and drain doping is considered the same and of the donor type with value of $\mathrm{N}_{\mathrm{D}}=1 \times 10^{18} \mathrm{~cm}^{-3}$. $\mathrm{Ga}_{\mathrm{X}} \mathrm{In}_{1-\mathrm{X}} \mathrm{As}$ is selected as a drain-channel material and the source is composed of $\mathrm{Ga}_{\mathrm{Y}} \mathrm{In}_{1-\mathrm{Y}} \mathrm{As}$. As shown in Fig. 1, the channel length, body thickness ( $\mathrm{Tb}$ ), and gate dielectric thickness ( $\left.\mathrm{T}_{\mathrm{OX}}\right)$ are $20 \mathrm{~nm}, 5 \mathrm{~nm}$, and $2 \mathrm{~nm}$, respectively. Drain/source extension length is $20 \mathrm{~nm}$. $\mathrm{HfO}_{2}$ is considered as a gate dielectric with $\mathrm{K}=25$. In the proposed structure, $\mathrm{SiO}_{2}$ acts between control gate (c-gate) and auxiliary gate (p-gate) as the isolation layer with the thickness of $\mathrm{W}_{\mathrm{SiO} 2}=2 \mathrm{~nm}$. The p-gate work function is $5.9 \mathrm{ev}$ and is achieved by considering Pt as the gate electrode [28]. The cgate work function is $4.3 \mathrm{eV}$ and can be obtained as metal using molybdenum with nitrogen implant dose [28]. The structural parameters of the VHJL-TFET device proposed in Fig. 1 are the same as those of HJL-TFET device proposed in [23] and[22] VHJL-TFET device shown in Fig. 1 is called $\mathrm{Ga}_{\mathrm{X}} \mathrm{In}_{1-\mathrm{X}} \mathrm{As} / \mathrm{Ga}_{\mathrm{Y}} \mathrm{In}_{1-\mathrm{Y}} \mathrm{Sb}$ VHJL-TFET.

In order to simulate the $\mathrm{Ga}_{\mathrm{X}} \mathrm{In}_{1-\mathrm{X}} \mathrm{As} / \mathrm{Ga}_{\mathrm{Y}} \mathrm{In}_{1-\mathrm{Y}} \mathrm{Sb}$ VHJL-TFET, a commercial tool is used. The nonlocal band to band tunneling (BTBT) model is considered to determine the electrical properties of the proposed device. Nonlocal BTBT model considers spatial variations of energy bands and quasi-fermi levels in tunneling path [22, 29]. The Hansch

(a)
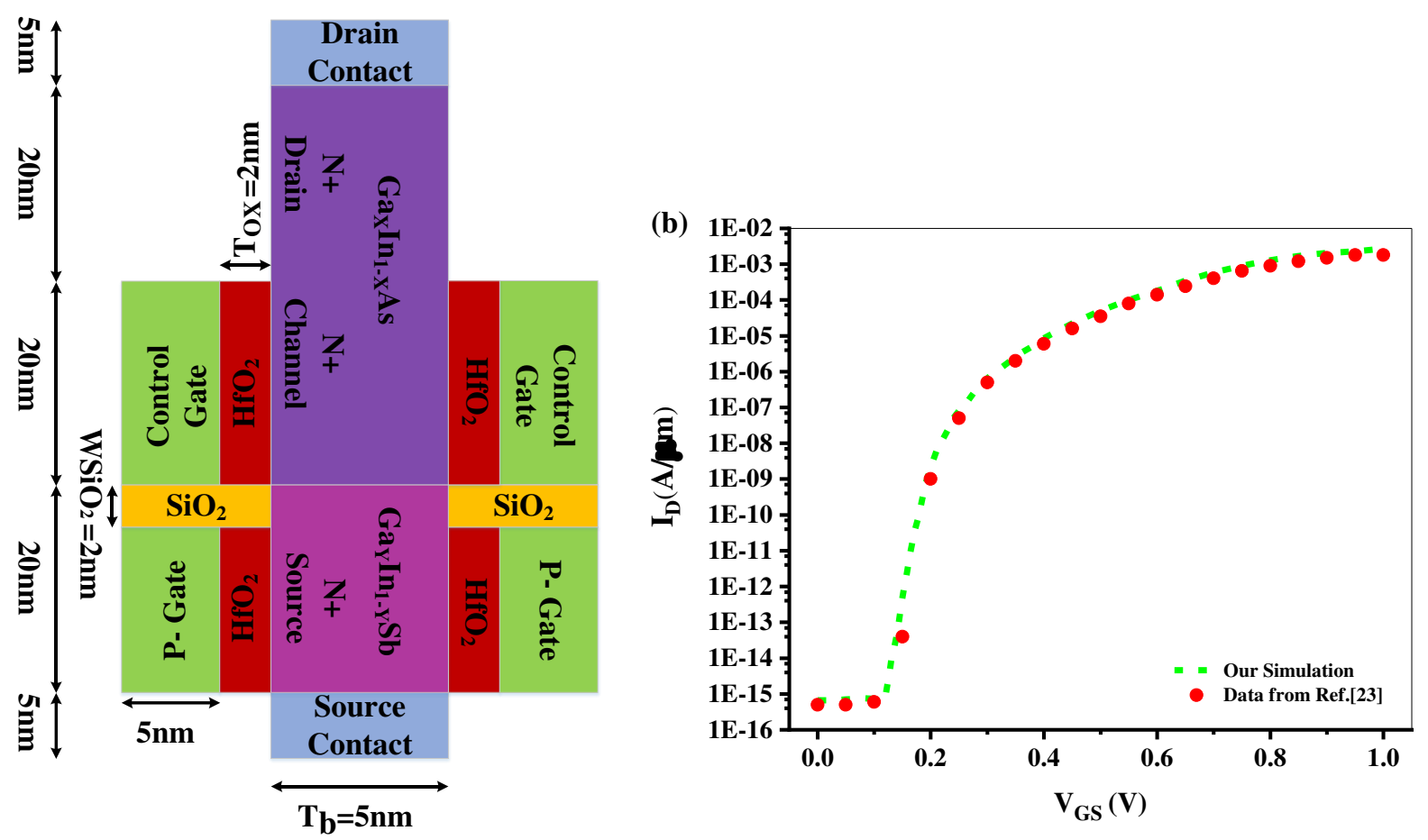

Fig. 1 (a) Device structure of a GaxIn $\operatorname{In}_{1-\mathrm{X} A s} / \mathrm{Gay}_{1-\mathrm{Y}} \mathrm{Sb}$ VHJL-TFET (not to scale) and (b) Calibration with the published result, ID-VGS characteristics of $20 \mathrm{~nm}$ gate length HJL-TFET reported in Ref.[23].

model is used to consider the quantum confinement effect as well as interface defects of oxide/semiconductor [12, 29]. The dependence of the mobility on the vertical electric field, doping concentration, and temperature is considered using Lombardi model $[22,29]$. The direct generation/recombination model as well as Shockley-ReadHall (SRH) recombination model is considered to determine the accurate leakage current value in the simulated devices [22, 29]. Given the high doping density in the proposed device, the band gap narrowing model is used [29, $30]$. With changes in $\mathrm{X}$ and $\mathrm{Y}$, in addition to changing energy band gap and electron affinity, the electron tunneling effective mass and hole tunneling effective mass are varied [27]. These changes are calculated based on [27] and are 
considered in the simulation. The effects of defects and nonsmoothness in the interfacial regions of $\operatorname{Gax}_{\mathrm{X}} \mathrm{In}_{1}$ $\mathrm{xAs} / \mathrm{Ga}_{\mathrm{Y}} \mathrm{In}_{1-\mathrm{Y}} \mathrm{Sb}$ layers are neglected in our simulations. These effects in real devices flat the $\mathrm{I}_{\mathrm{D}}-\mathrm{V}_{\mathrm{GS}}$ characteristics due to high electric field effects [30]. In GaX $\operatorname{In}_{1-X} \mathrm{As} / \mathrm{Ga}_{Y} \mathrm{In}_{1-\mathrm{Y}} \mathrm{Sb}$ VHJL-TFET device, instead of doping junctions in regular TFET devices, there is a junction between two semiconductors with the same doping. Therefore, Gax $\operatorname{In}_{1}$ $\mathrm{xAs} / \mathrm{Ga}_{\mathrm{Y}} \mathrm{In}_{1-\mathrm{Y}} \mathrm{Sb}$ VHJL-TFET is still categorized as a junctionless device

In order to show the accuracy of our simulations in this paper, we simulated the HJL-TFET with the structural parameters reported in [23]. The HJL-TFET device reported in [23] contains GaAs material in both drain and channel regions, and Ge material in the source region. Figure $1 \mathrm{~b}$ shows a comparison between our numerical simulations and simulation reported in [23]. Our numerical simulations are performed under the same conditions reported in [23]. As can be seen, the results of our numerical simulations are reasonably consistent with the simulation results reported in [23]. Therefore, the models used in the simulation in this study are sufficiently accurate.

\section{Results and Discussion}

Equation 1 shows the probability of tunneling in a TFET device, in which Wentzel-Kramers-Brillouin approximation is used $[12,16]$.

$T(E)=\exp \left(\frac{-4 \lambda \sqrt{m^{*}} E_{g}^{\frac{3}{2}}}{3 q h\left(\Delta \varphi+E_{g}\right)} \sqrt{\frac{\varepsilon_{\text {channel }}}{\varepsilon_{\text {oxide }}} T_{o x} T_{c h}}\right)$

Where $E_{g}$ is energy band gap, $h$ is Planck constant, $q$ is electron charge, $\lambda$ is screening length, $T_{o x}$ is gate dielectric thickness, and $\mathrm{T}_{\mathrm{ch}}$ is channel thickness. $\varepsilon_{\text {channel }}$ and $\varepsilon_{\text {oxide }}$ are relative permittivity of channel and gate dielectric, respectively. $\Delta \varphi$ is the energy difference between the valence band of the source and the conduction band of the channel, and $\mathrm{m}^{*}$ is tunneling effective mass [16]. In fact, Equation 1 shows that both parameters $\mathrm{E}_{\mathrm{g}}$ and $\mathrm{m}^{*}$ play an important role in the performance of the TFET device.

One of the main motivations for this study is to improve performance of GaX $\operatorname{In}_{1-X} A s / G_{Y} I_{1-Y} S b$ VHJL-TFET device proposed with changes in $\mathrm{X}$ and $\mathrm{Y}$ mole fractions. By changing the $\mathrm{X}$ and $\mathrm{Y}$ parameters, the electron tunneling effective mass $\left(\mathrm{m}_{\mathrm{e}}{ }^{*}\right)$, hole tunneling effective mass $\left(\mathrm{m}_{\mathrm{h}}{ }^{*}\right)$, energy band gap and electron affinity $(\mathrm{X})$ in source, channel and drain regions of GaX $\operatorname{In}_{1-X} \mathrm{As} / \mathrm{GaY}_{Y} \mathrm{In}_{1-\mathrm{Y}} \mathrm{Sb}$ VHJL-TFET device are affected, followed by changes in electrical properties of the simulated device.

Equations 2 and 3 show the electron tunneling effective mass and hole tunneling effective mass, respectively, in the drain-channel region (GaX $\left.\operatorname{In}_{1-X} A s\right)$ and source region $\left(\mathrm{GaY}_{\mathrm{Y}} \mathrm{In}_{1-\mathrm{Y}} \mathrm{Sb}\right)$ [27].

$$
\begin{aligned}
& \left\{\begin{array}{c}
m_{e}^{*}=\left(0.023+0.037 x+0.003 x^{2}\right) m_{0} \quad m_{h}^{*}=\left(m_{h h}^{3 / 2}+m_{l h}^{3 / 2}\right)^{2 / 3} \\
m_{h h}=(0.41+0.1 x) m_{0} \\
m_{l h}=(0.026+0.056 x) m_{0}
\end{array}\right. \\
& \left\{\begin{array}{c}
m_{e}^{*}=\left(0.014+0.0178 y+0.0092 y^{2}\right) m_{0} \quad m_{h}^{*}=\left(m_{h h}^{3 / 2}+m_{l h}^{3 / 2}\right)^{2 / 3} \\
m_{h h}=0.4 m_{0} \\
m_{l h}=\left(0.015+0.01 y+0.025 y^{2}\right) m_{0}
\end{array}\right.
\end{aligned}
$$

Where $m_{0}$ is the free electron mass, $m_{h h}$ is heavy hole mass, and $m_{h}$ is light hole mass. In Equations 2 and 3, at various $\mathrm{X}$ and $\mathrm{Y}, \mathrm{Gax}_{\mathrm{X}} \mathrm{In}_{1-\mathrm{X}} \mathrm{As}$ and $\mathrm{Ga}_{\mathrm{Y}} \mathrm{In}_{1-\mathrm{Y}} \mathrm{Sb}$ have direct band gap. Therefore, the electron effective mass is used at $\Gamma$ valley in the simulation [27]. 
Equations 4 and 5 show the energy band gap $\left(\mathrm{E}_{\mathrm{g}}\right)$ and electron affinity $(\mathrm{X})$, respectively, in the drain-channel region $\left(\mathrm{GaXIn}_{1-\mathrm{X}} \mathrm{As}\right)$ and source region $\left(\mathrm{GaY}_{\mathrm{Y}} \mathrm{In}_{1-\mathrm{Y}} \mathrm{Sb}\right)$ [27].

$$
\begin{gathered}
\left\{\begin{array}{c}
E_{g}=0.36+0.63 x+0.43 x^{2} \\
\chi=4.9-0.83 x
\end{array}\right. \\
\left\{\begin{array}{c}
E_{g}=0.172+0.139 y+0.415 y^{2} \\
\chi=4.59-0.53 y
\end{array}\right.
\end{gathered}
$$

Figure 2a shows the variations in the energy band gap and electron affinity, and Fig. 2b shows the variations in electron and hole tunneling effective mass in the drain-channel and source regions.

(a)

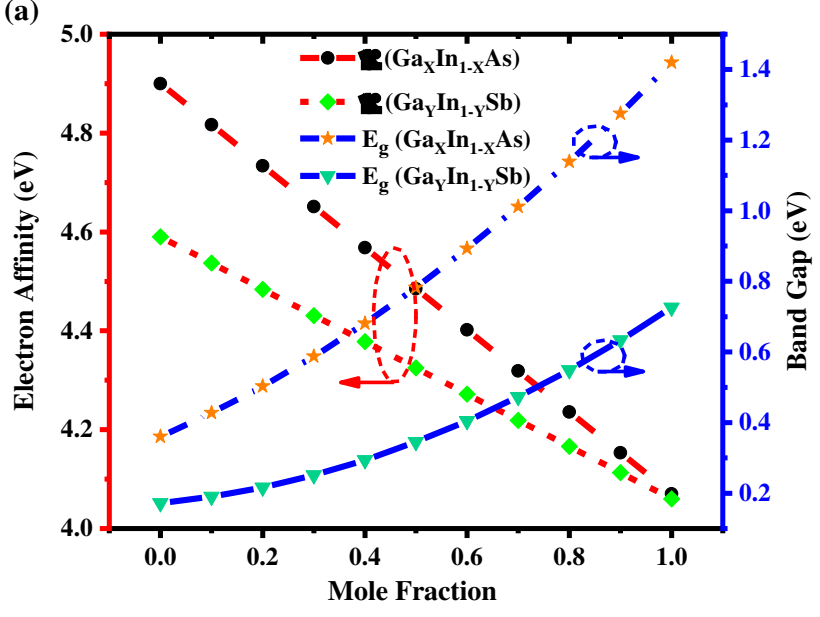

(b)

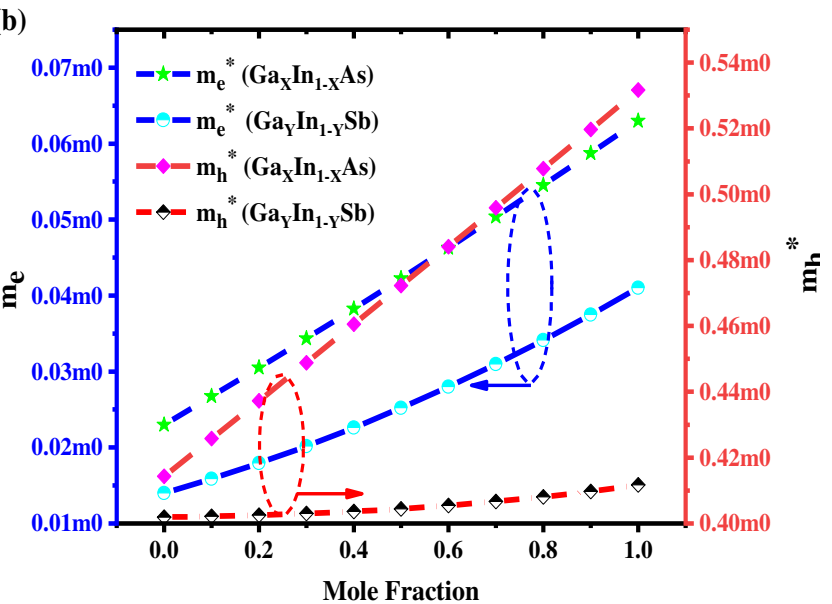

Fig.2 (a) Energy band gap and electron affinity as a function of $\mathrm{X}$ and $\mathrm{Y}$ mole fractions. (b) Electron tunneling effective mass and hole tunneling effective mass as a function of $\mathrm{X}$ and $\mathrm{Y}$ mole fractions.

As shown in Fig. 2a, for a given value of $\mathrm{X}=\mathrm{Y}$, the energy band gap in the source region $\left(\mathrm{Ga}_{\mathrm{Y}} \mathrm{In}_{1-\mathrm{Y}} \mathrm{Sb}\right)$ is lower than that in the channel region $\left(\mathrm{Ga}_{X} \operatorname{In}_{1-\mathrm{X}} \mathrm{As}\right)$. Also, for a given value of $\mathrm{X}=\mathrm{Y}$, with the simultaneous increase in mole fractions, the difference in energy band gap between source (GaYIn $\left.\operatorname{In}_{1-\mathrm{Y}} \mathrm{Sb}\right)$ and channel $\left(\mathrm{Gax}_{\mathrm{X}} \mathrm{In}_{1-\mathrm{X}} \mathrm{As}\right)$ is increased. The difference in electron affinity between $\mathrm{Ga}_{\mathrm{y}} \mathrm{In}_{1-\mathrm{y}} \mathrm{Sb}$ and $\mathrm{Ga}_{\mathrm{x}} \mathrm{In}_{1-\mathrm{x}} \mathrm{As}$ is reduced for a given value $\mathrm{X}=\mathrm{Y}$ with an increase in mole fractions and, for $\mathrm{X}=\mathrm{Y}=1$, the electron affinity of the two materials overlaps. Figure $2 \mathrm{~b}$ shows that for a given value of $\mathrm{X}=\mathrm{Y}$ with an increase in mole fractions, the tunneling effective mass of the electron and hole is increased for both materials and also the increased effective mass in $\mathrm{Ga}_{\mathrm{y}} \mathrm{In}_{1-\mathrm{y}} \mathrm{Sb}$ is negligible.

\subsection{Performance evaluation of the VHJL-TFET device for various mole fractions}

In this section, for the proposed structure $\mathrm{Ga}_{X} \mathrm{In}_{1-\mathrm{X}} \mathrm{As} / \mathrm{Ga}_{\mathrm{Y}} \mathrm{In}_{1-\mathrm{Y}} \mathrm{Sb}$ VHJL-TFET, $\mathrm{X}$ mole fraction is increased from 0 to 1 with steps of 0.05 ; for each step of $\mathrm{X}, \mathrm{Y}$ mole fraction is varied from 0 to 1 . For various $\mathrm{X}$ and $\mathrm{Y}$ changes, the digital benchmarking parameters of GaX $\operatorname{In}_{1-\mathrm{X}} \mathrm{As} / \mathrm{GaY}_{\mathrm{Y}} \mathrm{In}_{1-\mathrm{Y}} \mathrm{Sb}$ VHJL-TFET are investigated.

There are authoritative references [31] that considered $\mathrm{I}_{\mathrm{ON}}$ as a drain current for bias conditions $\mathrm{V}_{\mathrm{GS}}=\mathrm{V}_{\mathrm{DS}}=\mathrm{V}_{\mathrm{DD}}$ and, IOFF as a drain current for bias conditions $\mathrm{V}_{\mathrm{GS}}=0 \mathrm{~V}$ and $\mathrm{V}_{\mathrm{DS}}=\mathrm{V}_{\mathrm{DD}}$. In this study, $\mathrm{V}_{\mathrm{DD}}$ is considered to be $1 \mathrm{~V}$. Therefore, the drain current for bias conditions $\mathrm{V}_{\mathrm{GS}}=0 \mathrm{~V}$ and $\mathrm{V}_{\mathrm{DS}}=1 \mathrm{~V}$ is considered as $\mathrm{I}_{\mathrm{OFF}}$ and the drain current for bias conditions $\mathrm{V}_{\mathrm{GS}}=\mathrm{V}_{\mathrm{DS}}=1 \mathrm{~V}$ is considered as $\mathrm{I}_{\mathrm{ON}}$ [31]. Also, the gate-source voltage for drain current $10^{-7} \mathrm{~A} / \mathrm{um}$ is considered as the threshold voltage [31]. Examinations in this study show that changes in $\mathrm{X}$ and $\mathrm{Y}$ parameters, in addition to changing electron tunneling effective mass and hole tunneling effective mass, would change the energy band profile in the source/channel interface. The changes in energy band profile are in a way that type I, type II, and type III hetero structures are created in the source/channel interface in the OFF-state (see Figure 3 to 6). 
Figure 3a shows 2D matrix of $\mathrm{I}_{\mathrm{OFF}}$ changes and Fig. 3b shows 2D matrix of $\mathrm{I}_{\mathrm{ON}}$ changes with variations of $\mathrm{X}$ and $\mathrm{Y}$ parameters. As seen, with changes in $\mathrm{X}$ and $\mathrm{Y}$ parameters, I $\mathrm{ON}_{\mathrm{ON}}$ changes are one order of magnitude and $\mathrm{I}_{\mathrm{OFF}}$ changes are fourteen orders of magnitude. As a result, sensitivity of $\mathrm{I}_{\mathrm{OFF}}$ to changes in $\mathrm{X}$ and $\mathrm{Y}$ parameters, is higher than that of Ion. The regions of type I, type II and type III hetero structures in OFF-state are shown in Fig. 3a. Accordingly, for some $\mathrm{X}$ and $\mathrm{Y}$ values in the region related to type III hetero structure, $\mathrm{I}_{\mathrm{OFF}}$ is larger than $10^{-7} \mathrm{~A} / \mathrm{um}$. Therefore, in bias conditions $\mathrm{V}_{\mathrm{GS}}=0 \mathrm{~V}$ and $\mathrm{V}_{\mathrm{DS}}=1 \mathrm{~V}$, the device is not located in the sub-threshold region. Comparison of Fig. 3a and Fig. 2a shows that, with an increase in $\mathrm{X}=\mathrm{Y}$ in the region related to type II hetero
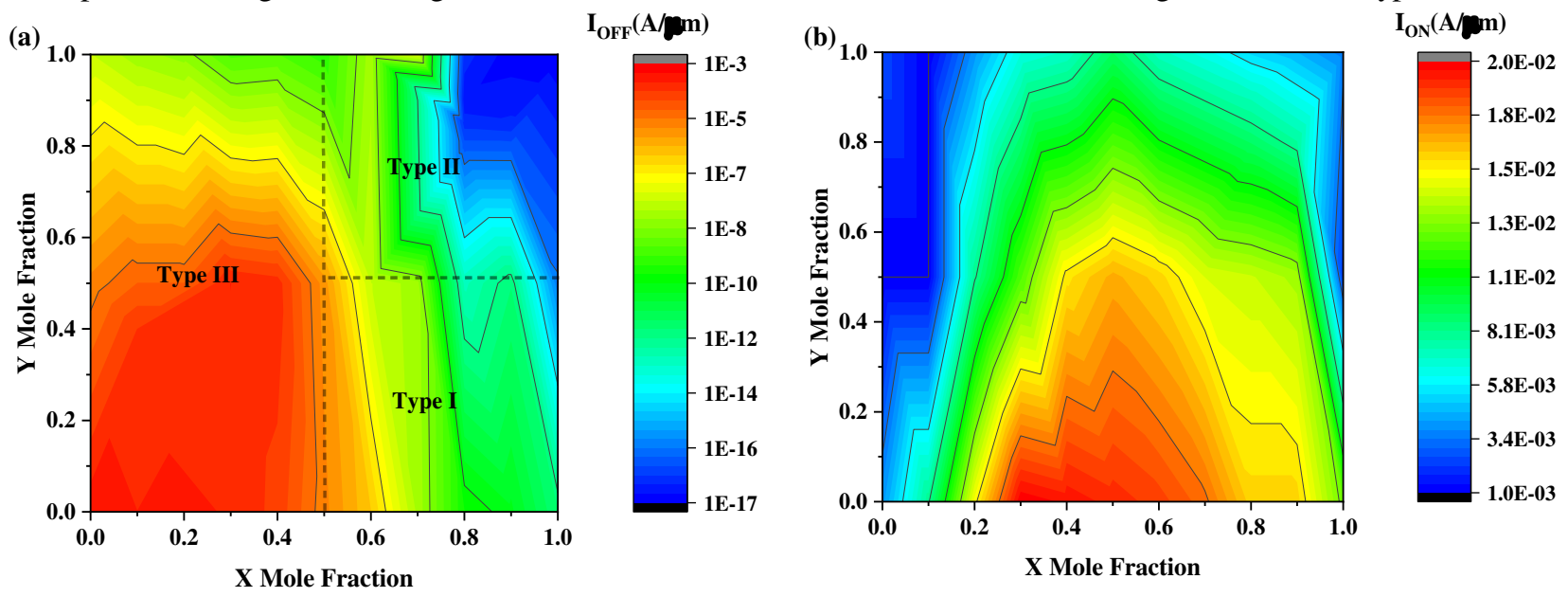

Fig. $32 \mathrm{D}$ variation matrix of (a) OFF-state current (IOFF) and (b) ON-state current ( $\mathrm{I}_{\mathrm{ON}}$ ) as a function of $\mathrm{X}$ and $\mathrm{Y}$ mole fractions. ION is measured at bias conditions of $\mathrm{V}_{\mathrm{GS}}=1 \mathrm{~V}, \mathrm{~V}_{\mathrm{DS}}=1 \mathrm{~V}$. IofF is measured at bias conditions of $\mathrm{V}_{\mathrm{GS}}=0 \mathrm{~V}, \mathrm{~V}_{\mathrm{DS}}=1 \mathrm{~V}$.

structure, the electron and hole tunneling effective mass increases. As a result, the probability of tunneling based on Equation 1 is reduced and, consequently, IOFF is decreased. Our simulation results show that the tunneling width is reduced in $\mathrm{ON}$-state for the values of $\mathrm{X}$ and $\mathrm{Y}$ in the red region in Fig. 3b. As a result, Ion is increased in this region for the proposed GaXX $\mathrm{In}_{1-\mathrm{X}} \mathrm{As} / \mathrm{Ga}_{\mathrm{Y}} \mathrm{In}_{1-\mathrm{Y}} \mathrm{Sb}$ VHJL-TFET device.

Average SS in TFET is one of the most important parameters to evaluate switching performance from IOFF to ION. In
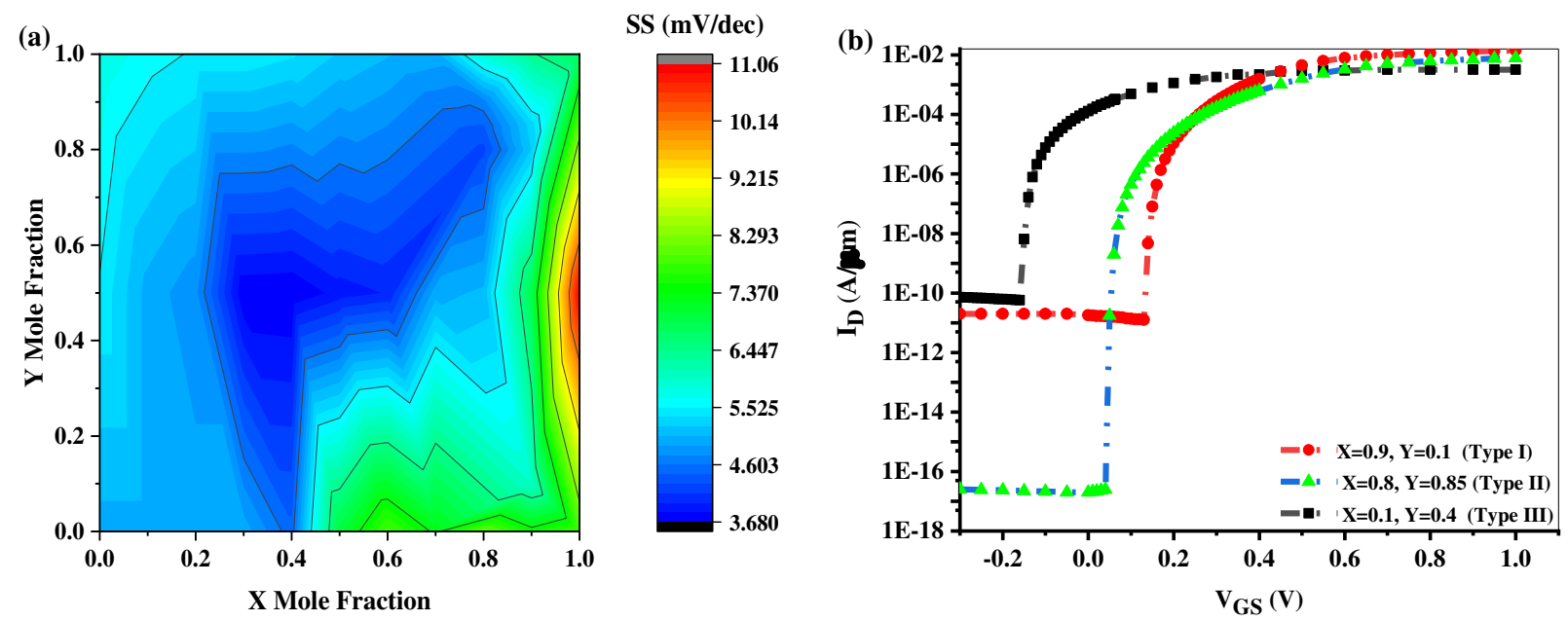

Fig.4 (a) 2D variation matrix of average subthreshold slope (SS) as a function of X and Y mole fractions. 1 V. Average SS of simulated structures has been calculated based on the method discussed in [22, 32]. (b) Input characteristics of GaxIn 1 -

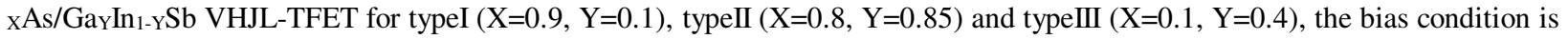
$\mathrm{VDS}=1 \mathrm{~V}$. 
this study, the average SS is considered between a point where the drain current is raised with an increase in gate voltage and threshold voltage [22, 32]. Figure 4a shows the contour of the changes in average SS by changing the $X$ and $\mathrm{Y}$ parameters. The lower average SS in GaXIn ${ }_{1-\mathrm{X}} \mathrm{As} / \mathrm{Ga}_{\mathrm{Y}} \mathrm{In}_{1-\mathrm{Y}} \mathrm{Sb}$ VHJL-TFET indicates higher switching rate [15, $22,32]$.

In this study, the optimal selection of $\mathrm{X}$ and $\mathrm{Y}$ values to improve the digital benchmarking parameters of $\operatorname{Gax}_{\mathrm{X}} \mathrm{In}_{1}$ $\mathrm{xAs} / \mathrm{GaY}_{\mathrm{Y}} \mathrm{In}_{1-\mathrm{Y}} \mathrm{SbVHJL}-\mathrm{TFET}$ device are carried out by considering the following priorities:

1. I $\mathrm{I}_{\mathrm{OFF}}$ must be of the fA/um order or smaller, because in TFET devices, the $\mathrm{I}_{\mathrm{OFF}}$ is expected to be of the fA/um order at the most [32].

2. Average SS must be smaller than $10 \mathrm{mV} / \mathrm{dec}$, because the TFET device with $\mathrm{SS}<10 \mathrm{mV} / \mathrm{dec}$ is very suitable for sub-0.5V supply voltage applications $[11,33]$.

3. $\mathrm{I}_{\mathrm{ON}}$ must be of the $\mathrm{mA} / \mathrm{um}$ order, because in TFET devices with $\mathrm{I}_{\mathrm{ON}}$ from $\mathrm{mA} / \mathrm{um}$ order, it can be said that the problems caused by the decreased $\mathrm{I}_{\mathrm{ON}}$ are eliminated [15-18, 22].
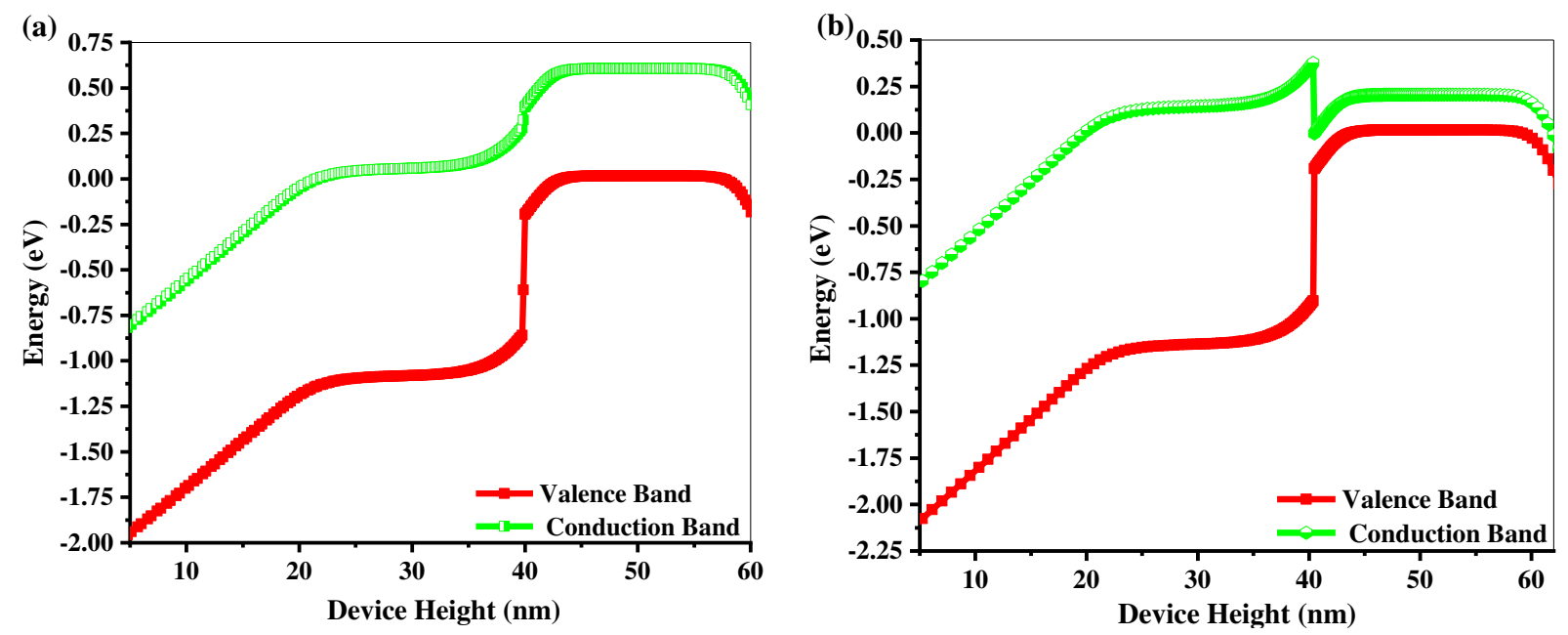

Fig.5 Energy band diagram, taken vertically across the GaxIn $1-\mathrm{XAs} / \mathrm{GaY} \operatorname{In}_{1-\mathrm{Y}} \mathrm{Sb}$ VHJL-TFET for (a) typeII (X=0.8, Y=0.85) and (b) typeI $(\mathrm{X}=0.9, \mathrm{Y}=0.1)$. The bias conditions are as follows $\mathrm{V}_{\mathrm{GS}}=0 \mathrm{~V}, \mathrm{~V}_{\mathrm{DS}}=1 \mathrm{~V}$.

According to the priorities mentioned above, the optimal mole fractions are selected equal to $\mathrm{X}=0.8$ and $\mathrm{Y}=0.85$ to improve the performance of the proposed GaxIn $\operatorname{In}_{1-\mathrm{X}} \mathrm{As} / \mathrm{Ga}_{Y} \mathrm{In}_{1-\mathrm{Y}} \mathrm{Sb}$ VHJL-TFET structure. In $\mathrm{Ga}_{0.8} \mathrm{In}_{0.2} \mathrm{As} / \mathrm{Ga}_{0.85} \mathrm{In}_{0.15} \mathrm{Sb}$ VHJL-TFET device shown in Fig. 1, we have $\mathrm{I}_{\mathrm{OFF}}=0.02 \mathrm{fA} / \mathrm{um}, \mathrm{I}_{\mathrm{ON}}=8 \mathrm{~mA} / \mathrm{um}$, $\mathrm{SS}=4.4 \mathrm{mV} / \mathrm{dec}$. The contours of Fig. 3a show that, for $\mathrm{X}=0.8$ and $\mathrm{Y}=0.85$, the IoFF is reduced compared to other values of $X$ and $Y$. The contours of Fig. $3 b$ also show that, for $X=0.8$ and $Y=0.85$, Ion of the proposed device is reasonable compared to the other values of $\mathrm{X}$ and $\mathrm{Y}$. As a result, in the proposed device for $\mathrm{X}=0.8$ and $\mathrm{Y}=0.85$, $\mathrm{I}_{\mathrm{ON}} / \mathrm{I}_{\mathrm{OFF}}$ ratio is increased. The contour of Fig. $4 \mathrm{a}$ also shows the average $\mathrm{SS}$ of $\mathrm{Ga}_{0.8} \mathrm{In}_{0.2} \mathrm{As} / \mathrm{Ga}_{0.85} \mathrm{In}_{0.15} \mathrm{Sb}$ VHJLTFET device is smaller than $10 \mathrm{mV} / \mathrm{dec}$, and is improved compared to other values of $\mathrm{X}$ and $\mathrm{Y}$.

For studying the band structure of the proposed $\mathrm{Ga}_{\mathrm{X}} \mathrm{In}_{1-\mathrm{X}} \mathrm{As} / \mathrm{Ga}_{\mathrm{Y}} \mathrm{In}_{1-\mathrm{Y}} \mathrm{Sb}$ VHJL-TFET device, it is not possible to display the energy band profile for all $\mathrm{X}$ and $\mathrm{Y}$ values. In this study, $\mathrm{X}=0.9, \mathrm{Y}=0.1$ and $\mathrm{X}=0.8, \mathrm{Y}=0.85$, and $\mathrm{X}=0.1$, $\mathrm{Y}=0.4$ are considered for the hetero structure of type I, type II, and type III, respectively. Fig. $4 \mathrm{~b}$ shows the currentvoltage input characteristic of the simulated devices for different values of $\mathrm{X}$ and $\mathrm{Y}$. As seen:

1. I IFF of the simulated device with $\mathrm{X}=0.8, \mathrm{Y}=0.85$ is much lower than the other simulated devices.

2. $\mathrm{Ga}_{0.8} \mathrm{In}_{0.2} \mathrm{As} / \mathrm{Ga}_{0.85} \mathrm{In}_{0.15} \mathrm{Sb}$ VHJL-TFET device is turned $\mathrm{ON}$ for gate voltage of less than $0.1 \mathrm{~V}$. 
3. $\mathrm{I}_{\mathrm{ON}}$ of the simulated devices is approximately the same.

4. The simulated device with $\mathrm{X}=0.1$ and $\mathrm{Y}=0.4$ has the $\mathrm{I}_{\mathrm{OFF}}$ larger than $7 \mathrm{~A} / \mathrm{um}$. Therefore, it will not turn off at $\mathrm{V}_{\mathrm{GS}}=0 \mathrm{~V}$.

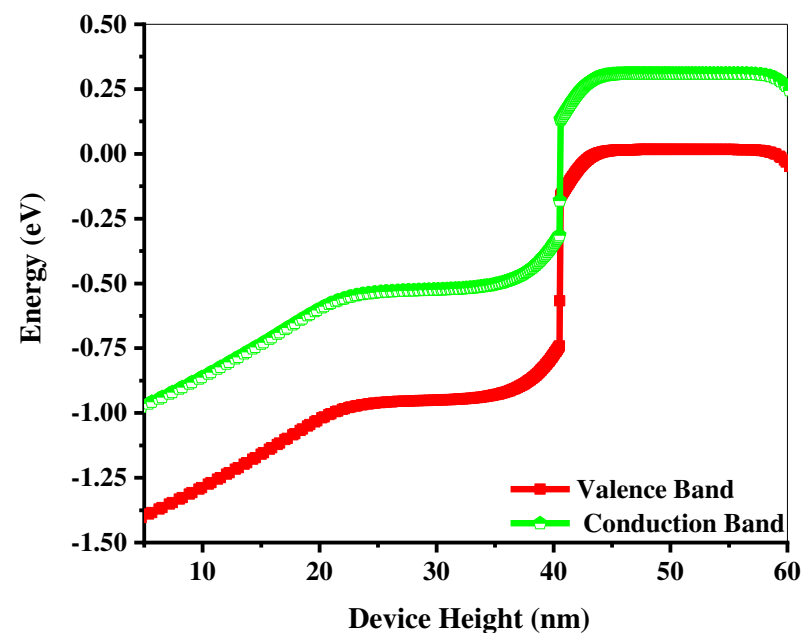

Fig. 6 Energy band diagram, taken vertically across the $\mathrm{Ga}_{0.1} \mathrm{In}_{0.9} \mathrm{As} / \mathrm{Ga}_{0.4} \mathrm{In}_{0.6} \mathrm{Sb}$ VHJL-TFET (i.e. typeIII).

Figure 5a and Fig. 5b show the energy band profile for simulated structures with $\mathrm{X}=0.8$ and $\mathrm{Y}=0.85$ (type II hetero structure) and $\mathrm{X}=0.9$ and $\mathrm{Y}=0.1$ (type I hetero structure) in bias conditions of OFF-state. In addition, the energy band profile in bias conditions of OFF-state for $\mathrm{X}=0.1$ and $\mathrm{Y}=0.4$ (type III hetero structure) is shown in Fig. 6. Figure 7a compares the energy band diagram of type I, type II, and type III hetero structures in vicinity of the source/channel interface in OFF-state for the simulated structures.

(a)

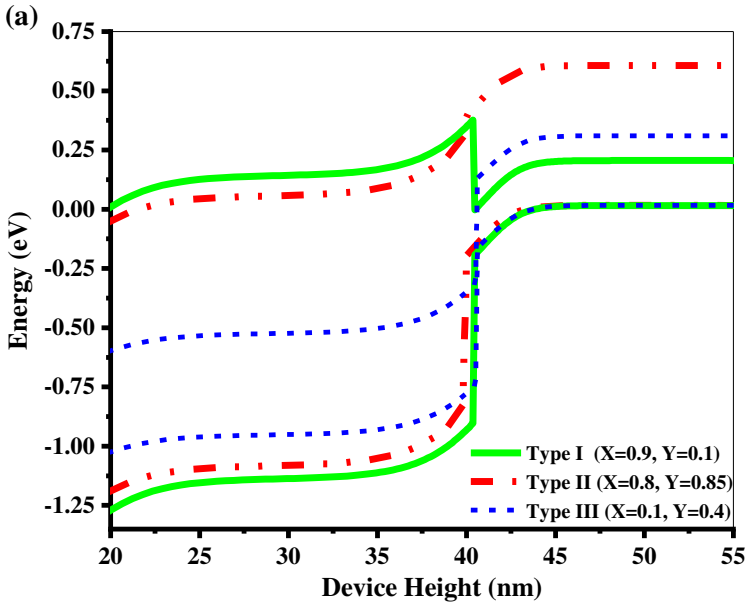

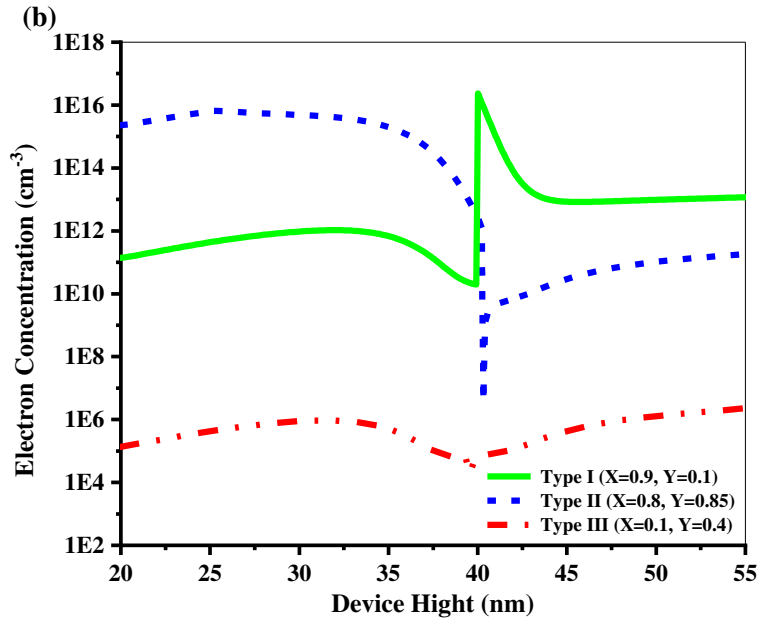

Fig. 7 (a) Energy band diagram comparison and (b) electron concentration comparison between type I, type II, and type III heterostructures at the vicinity of the source/channel interface. The bias conditions are as follows $V_{G S}=0 \mathrm{~V}, V_{D S}=1 \mathrm{~V}$.

Overlap of source valence band and channel conduction band for $\mathrm{X}=0.8$ and $\mathrm{Y}=0.85$ is small enough to not allow the electron tunneling from the source valence band to the channel conduction band (see Fig. 5a). Additionally, for $\mathrm{X}=0.8$ and $\mathrm{Y}=0.85$, electron tunneling effective mass and hole tunneling effective mass are increased (see Fig. 2b). As a result, in the OFF-state, the probability of electron tunneling from the source valence band to the channel conduction band based on Equation 1 is reduced, followed by significant degradation in IofF. Despite the increased 
tunneling effective mass for $\mathrm{X}=0.8$ and $\mathrm{Y}=0.85$ compared to the other $\mathrm{X}$ and $\mathrm{Y}$ values, $\mathrm{I}_{\mathrm{ON}}$ of the proposed device is reasonable. This is because for $\mathrm{X}=0.8$ and $\mathrm{Y}=0.85$ in $\mathrm{ON}$-state, the increased tunneling effective mass is compensated for by reduced tunneling barrier width in source/channel interface. Given that $\mathrm{Ga}_{0.8} \mathrm{In}_{0.2} \mathrm{As} / \mathrm{Ga}_{0.85} \mathrm{In}_{0.15} \mathrm{Sb}$ VHJL-TFET is turned on for gate voltage below $0.1 \mathrm{~V}$.

In the OFF state, high overlap of source valence band and channel conduction band in the type III hetero structure allows electron tunneling (see Fig. 6). As a result, the $\mathrm{I}_{\mathrm{OFF}}$ of GaXIn $\operatorname{In}_{1-\mathrm{X}} \mathrm{As} / \mathrm{Ga}_{\mathrm{Y}} \mathrm{In}_{1-\mathrm{Y}} \mathrm{Sb}$ VHJL-TFET is increased with $\mathrm{X}=0.1$ and $\mathrm{Y}=0.4$. The simulation results show that the quantum well formed in the conduction band in the source/channel interface for the type I hetero structure (see Fig. 5b). Accordingly, electron concentration is increased in the source/channel interface, see Fig. 7b. As a result, channel conductance is increased, followed by $\mathrm{I}_{\mathrm{OFF}}$ increases. For simulated structures, $\mathrm{I}_{\mathrm{OFF}}$ of type I is larger than that of type II and less than that of type III.

By examining energy band profile of $\mathrm{Ga}_{\mathrm{X}} \mathrm{In}_{1-\mathrm{X}} \mathrm{As} / \mathrm{Ga}_{\mathrm{Y}} \mathrm{In}_{1-\mathrm{Y}} \mathrm{Sb}$ VHJL-TFET with type II hetero structure $(\mathrm{X}=0.8$, $\mathrm{Y}=0.85$ ) in OFF-state, it can be said that with slight changes in gate voltage, the Zener breakdown occurs in source/channel interface. As a result, the device switches from IoFF to I $\mathrm{ON}_{\mathrm{N}}$. Moreover, the I IFF in Gax $\mathrm{In}_{1-\mathrm{X}} \mathrm{As} / \mathrm{Ga}_{\mathrm{Y}} \mathrm{In}_{1-}$ YSb VHJL-TFET with type II hetero structure is from fA/um order.

Our simulation results show that using a material with a larger band gap in the drain-channel region and a material with a smaller band gap in the source region in proposed VHJL-TFET (i.e. $\operatorname{Eg}_{\text {GaXIn1-XAs }}>\operatorname{Eg}_{\text {GaYIn1-YSb }}$ ) significantly reduces the ambipolarity behavior. This result is compatible with another study [23].

\subsection{Importance of structural parameters in performance of VHJL-TFET device}

Simulations carried out in this study show that the doping concentration $\left(\mathrm{N}_{\mathrm{D}}\right)$, body thickness $\left(\mathrm{T}_{\mathrm{b}}\right)$, and spacer width between PG and CG $\left(\mathrm{W}_{\mathrm{SiO}_{2}}\right)$ are among the most important design parameters for the performance of VHJL-TFET

(a)

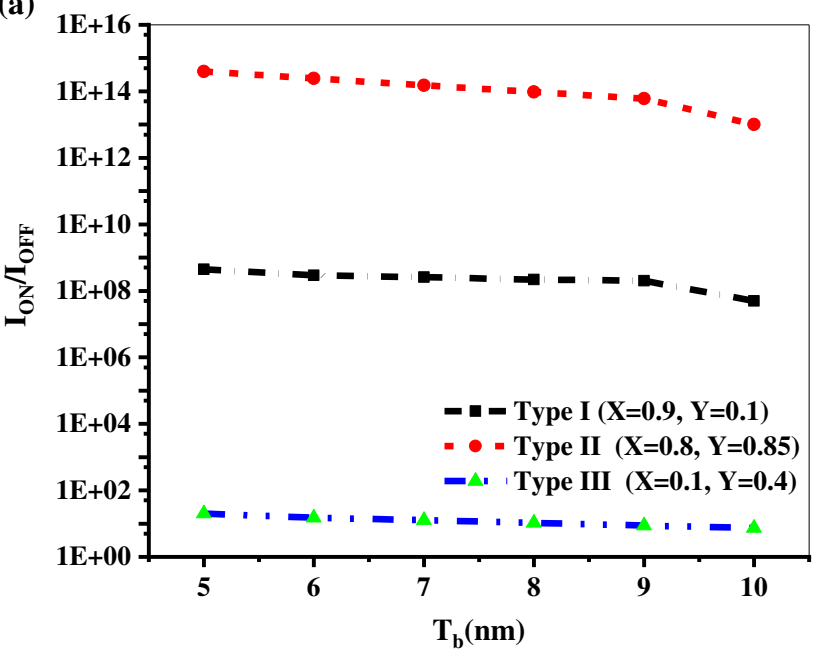

(b)

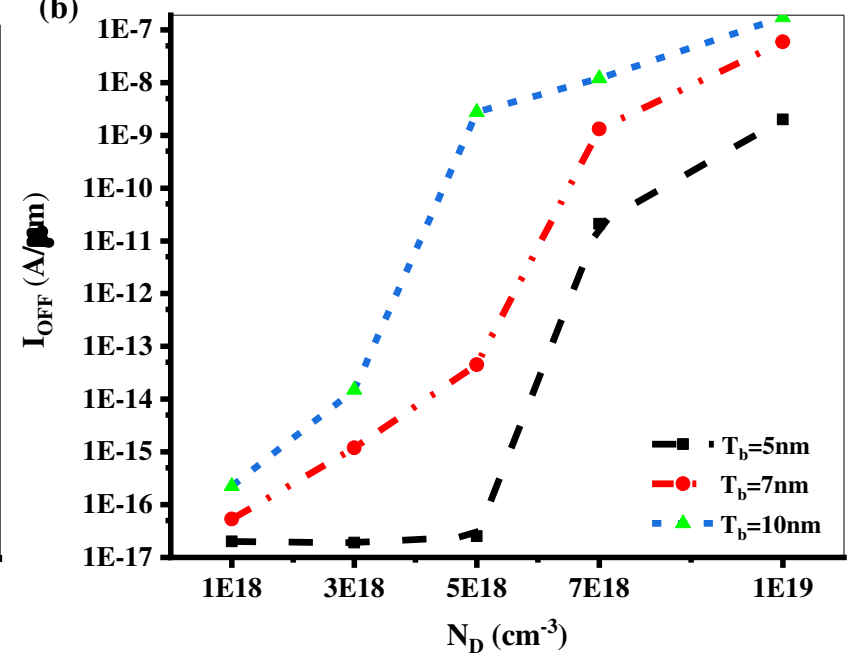

Fig. 8 (a) ON/OFF current ration as a function of body thickness ( $T_{b}$ ) of Gax In $1-\mathrm{X}$ As/Gay $\operatorname{In}_{1-Y}$ Sb VHJL-TFET with $\mathrm{N}_{\mathrm{D}}=1 \times 10^{18} \mathrm{~cm}^{-3}$ for various mole fractions. (b) IofF as a function of doping concentration $\left(\mathrm{N}_{\mathrm{D}}\right.$ ) of $\mathrm{Ga}_{0.8} \mathrm{In}_{0.2} \mathrm{As} / \mathrm{Ga}_{0.85} \mathrm{In}_{0.15} \mathrm{As}$ VHJL-TFET for various body thicknesses. Ion is measured at bias conditions of $\mathrm{V}_{\mathrm{GS}}=1 \mathrm{~V}, \mathrm{~V}_{\mathrm{DS}}=1 \mathrm{~V}$. IofF is measured at bias conditions of $\mathrm{V}_{\mathrm{GS}}=0 \mathrm{~V}, \mathrm{~V}_{\mathrm{DS}}=1 \mathrm{~V}$.

device.

$\mathrm{I}_{\mathrm{ON}} / \mathrm{I}_{\mathrm{OFF}}$ ratio as a function of $\mathrm{T}_{\mathrm{b}}$ for different types of hetero structures is shown in Fig. $8 \mathrm{a}$. As seen, the $\mathrm{I}_{\mathrm{ON}} / \mathrm{I}_{\mathrm{OFF}}$ ratio for a given type is increased by reducing $T_{b}$. Simulation results show by reducing $T_{b}$, the $C G$ ability to deplete 
the channel is increased in the OFF-state. Consequently, channel resistance is increased by reducing $\mathrm{T}_{\mathrm{b}}$, and the $\mathrm{I}_{\mathrm{OFF}}$ is significantly reduced. This is reflected in the increased $\mathrm{I}_{\mathrm{ON}} / \mathrm{I}_{\mathrm{OFF}}$ ratio.

As shown in Section 3.1, the high overlap of the source valence band and channel conduction band in the simulated devices with type III hetero structure increases the $\mathrm{I}_{\mathrm{OFF}}$. As a result, the increased $\mathrm{I}_{\mathrm{ON}} / \mathrm{I}_{\mathrm{OFF}}$ ratio by reducing $\mathrm{T}_{\mathrm{b}}$ for $\mathrm{Ga}_{0.1} \mathrm{In}_{0.9} \mathrm{As} / \mathrm{Ga}_{0.4} \mathrm{In}_{0.6} \mathrm{Sb}$ VHJL-TFET is negligible (see Fig. 8a). Also, Fig. 8a shows the $\mathrm{I}_{\mathrm{ON}} / \mathrm{I}_{\mathrm{OFF}}$ ratio for a given $\mathrm{T}_{\mathrm{b}}$ for $\mathrm{Ga}_{0.8} \mathrm{In}_{0.2} \mathrm{As} / \mathrm{Ga}_{0.85} \mathrm{In}_{0.15} \mathrm{Sb}$ VHJL-TFET is larger than the devices simulated with type I and type III hetero structures, because IOFF of the simulated device with type II hetero structure is less than other simulated devices.

Our simulation results show that the sensitivity of the $\mathrm{I}_{\mathrm{OFF}}$ to increased $\mathrm{N}_{\mathrm{D}}$ is higher than the sensitivity of $\mathrm{I}_{\mathrm{ON}}$. In fact, the channel resistance depends on $\mathrm{N}_{\mathrm{D}}$, accordingly, $\mathrm{N}_{\mathrm{D}}$ plays an important role in determining drain current. Channel resistance has been decreased due to positive control gate voltage in the $\mathrm{ON}$-state, and its value is smaller than channel resistance in the OFF-state. As a result, the sensitivity of the $\mathrm{I}_{\mathrm{OFF}}$ to increased $\mathrm{N}_{\mathrm{D}}$ is higher than the sensitivity of $\mathrm{I}_{\mathrm{ON}}$.

We investigated the performance of $\mathrm{Ga}_{0.8} \mathrm{In}_{0.2} \mathrm{As} / \mathrm{Ga}_{0.85} \mathrm{In}_{0.15} \mathrm{Sb}$ VHJL-TFET in OFF-state for different NDs between $1 \mathrm{E} 18$ and $1 \mathrm{E} 19$. Figure $8 \mathrm{~b}$ shows $\mathrm{I}_{\mathrm{OFF}}$ as a function of $\mathrm{N}_{\mathrm{D}}$ for different body thickness of $\mathrm{Ga}_{0.8} \mathrm{In}_{0.2} \mathrm{As} / \mathrm{Ga}_{0.85} \mathrm{In}_{0.15} \mathrm{Sb}$ VHJL-TFET. Our simulation results for a given $T_{b}$ show that, the channel resistance is reduced in OFF-state by increasing $\mathrm{N}_{\mathrm{D}}$. As a result, the $\mathrm{I}_{\mathrm{OFF}}$ is increased (see Fig. 8b). Also, the CG ability to deplete the channel is increased by $\mathrm{T}_{b}$ reducing for a given $\mathrm{N}_{\mathrm{D}}$ in OFF-state; therefore, $\mathrm{I}_{\mathrm{OFF}}$ is decreased.

The slope of the $\mathrm{I}_{\mathrm{OFF}}$ versus $\mathrm{N}_{\mathrm{D}}$ curve increases by increasing $\mathrm{N}_{\mathrm{D}}$, and this is more pronounced for larger body thicknesses, see Fig. 8b. First, the curve slope increases slowly and, then, increases rapidly. The rapid increase of slope for larger $T_{b} s$ begins at smaller $N_{D S}$. As a result, as $T_{b}$ increases, the sensitivity of $I_{O F F}$ to $N_{D}$ increases. As
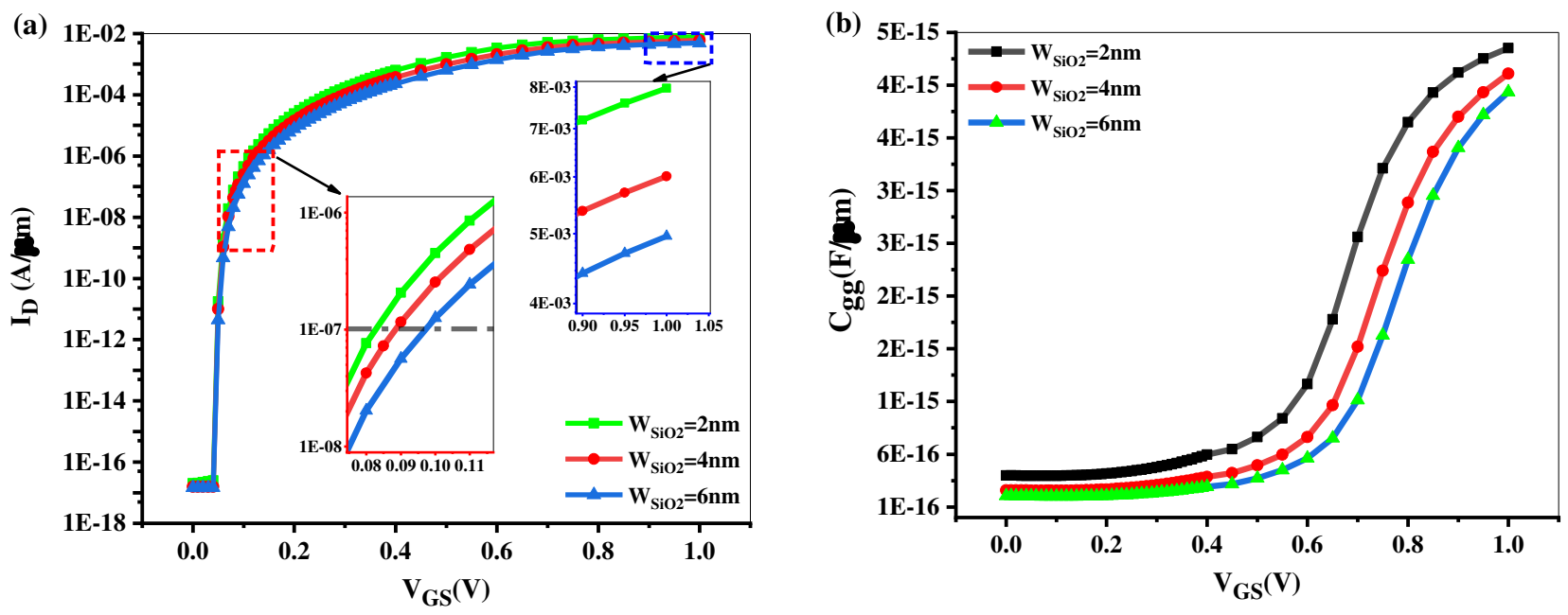

Fig.9 (a) Drain current and (b) the total gate-to-gate capacitance as a function of gate bias of Ga0.8 $\mathrm{In}_{0.2} \mathrm{As} / \mathrm{Ga}_{0.85} \mathrm{In}_{0.15} \mathrm{As}$ VHJLTFET for various $\mathrm{W}_{\mathrm{SiO} 2}$. The inset of Fig. 9(a) shows the $\mathrm{I}_{\mathrm{D}}-\mathrm{V}_{\mathrm{GS}}$ of simulate device in above threshold region. The bias condition is $\mathrm{V}_{\mathrm{DS}}=1 \mathrm{~V}$.

expected, with an increase in $\mathrm{N}_{D}$ for more $\mathrm{CG}$ control over the channel, the body thickness should be thinner.

The simulation results show that the performance of $\mathrm{Ga}_{0.8} \mathrm{In}_{0.2} \mathrm{As} / \mathrm{Ga}_{0.85} \mathrm{In}_{0.15} \mathrm{Sb}$ VHJL-TFET is dependent on the $\mathrm{W}_{\mathrm{SiO} 2}$. In this study, to investigate the effect of $\mathrm{W}_{\mathrm{SiO} 2}$ on the performance of the proposed $\mathrm{Ga}_{0.8} \mathrm{In}_{0.2} \mathrm{As} / \mathrm{Ga}_{0.85} \mathrm{In}_{0.15} \mathrm{Sb}$ VHJL-TFET in Fig. 1, $\mathrm{W}_{\mathrm{SiO} 2}$ is varied from $2 \mathrm{~nm}$ to $6 \mathrm{~nm}$. Figure $9 \mathrm{a}$ shows the $\mathrm{I}_{\mathrm{D}}-\mathrm{V}_{\mathrm{GS}}$ characteristic of $\mathrm{Ga}_{0.8} \mathrm{In}_{0.2} \mathrm{As} / \mathrm{Ga}_{0.85} \mathrm{In}_{0.15} \mathrm{Sb}$ VHJL-TFET for various values of $\mathrm{W}_{\mathrm{SiO} 2}$. The inset of Fig. 9a shows the performance of 
the simulated devices in the above threshold region. $\mathrm{As}_{\mathrm{SiO}_{2}}$ increases, the slope of the energy band diagram at the tunneling junction is reduced in the source/channel interface. As a result, electron tunneling in ON-state is reduced followed by decreased Ion. This is reflected in larger values by threshold voltage shift (see Fig. 9a). Based on the simulations, as $\mathrm{W}_{\mathrm{SiO} 2}$ varies from $2 \mathrm{~nm}$ to $6 \mathrm{~nm}$, I $\mathrm{INN}_{\mathrm{N}}$ is reduced by $37 \%$.

The total gate-to-gate capacitance $\left(\mathrm{C}_{\mathrm{gg}}\right)$, plays an important role in determining the intrinsic gate delay of a transistor $(\tau)$ for digital applications [22]. Figure $9 \mathrm{~b}$ shows $\mathrm{C}_{\mathrm{gg}}$ as a function of $\mathrm{V}_{\mathrm{GS}}$ for $\mathrm{Ga}_{0.8} \mathrm{In}_{0.2} \mathrm{As} / \mathrm{Ga}_{0.85} \mathrm{In}_{0.15} \mathrm{Sb}$ VHJL-TFET and for various values of $\mathrm{W}_{\mathrm{SiO} 2}$. We assume $\mathrm{V}_{\mathrm{DS}}=\mathrm{V}_{\mathrm{DD}}=1 \mathrm{~V}$ for calculating $\mathrm{C}_{\mathrm{gg}}$ and sweep gate voltage between 0 and $1 \mathrm{~V}$ at a frequency of $1 \mathrm{MHz}$ [22]. Our simulation results show that, with an increase in $\mathrm{W}_{\mathrm{SiO} 2}$, the gate-source capacitance decreases. As a result, $\mathrm{C}_{\mathrm{gg}}$ is reduced, which is more evident in the above threshold region.

Intrinsic gate delay $(\tau)$ is as follows $[22,30]$.

$$
\tau=\frac{C_{g g} V_{D D}}{I_{O N}}
$$

Table 1 Intrinsic gate delay comparison for various $\mathrm{W}_{\mathrm{SiO} 2}$ in the Ga0.8In $0.2 \mathrm{As} / \mathrm{Ga} 0.85 \operatorname{In}_{0.15} \mathrm{Sb}$ VHJL-TFET device.

\begin{tabular}{llll}
\hline $\mathrm{W}_{\mathrm{SiO} 2}$ & $\mathrm{I}_{\mathrm{ON}}(\mathrm{mA} / \mu \mathrm{m})$ & $\mathrm{C}_{\mathrm{gg}}(\mathrm{fF} / \mu \mathrm{m})$ & $\begin{array}{l}\text { Delay }(\tau) \\
(\mathrm{pS} / \mu \mathrm{m})\end{array}$ \\
\hline $2 \mathrm{~nm}$ & 8 & 4.54 & 0.57 \\
$4 \mathrm{~nm}$ & 6 & 4.21 & 0.70 \\
$6 \mathrm{~nm}$ & 5 & 4.04 & 0.81 \\
\hline
\end{tabular}

Where $\mathrm{V}_{\mathrm{DD}}=1 \mathrm{~V}$ refers to supply voltage and $\mathrm{IoN}_{\mathrm{ON}}$ refers to $\mathrm{ON}$-state current. Table 1 compares the values of $\tau$, Ion and $\mathrm{C}_{\mathrm{gg}}$ in bias conditions $\mathrm{V}_{\mathrm{GS}}=\mathrm{V}_{\mathrm{DS}}=1 \mathrm{~V}$. To calculate $\tau$, the device width is considered to be $1 \mu \mathrm{m}[22,30]$. As expected, with an increase in $\mathrm{W}_{\mathrm{SiO} 2}$, $\mathrm{I}_{\mathrm{ON}}$ and $\mathrm{C}_{\mathrm{gg}}$ are decreased. According to Equation 2, $\mathrm{I}_{\mathrm{ON}}$ has a direct impact and $\mathrm{C}_{\mathrm{gg}}$ has an

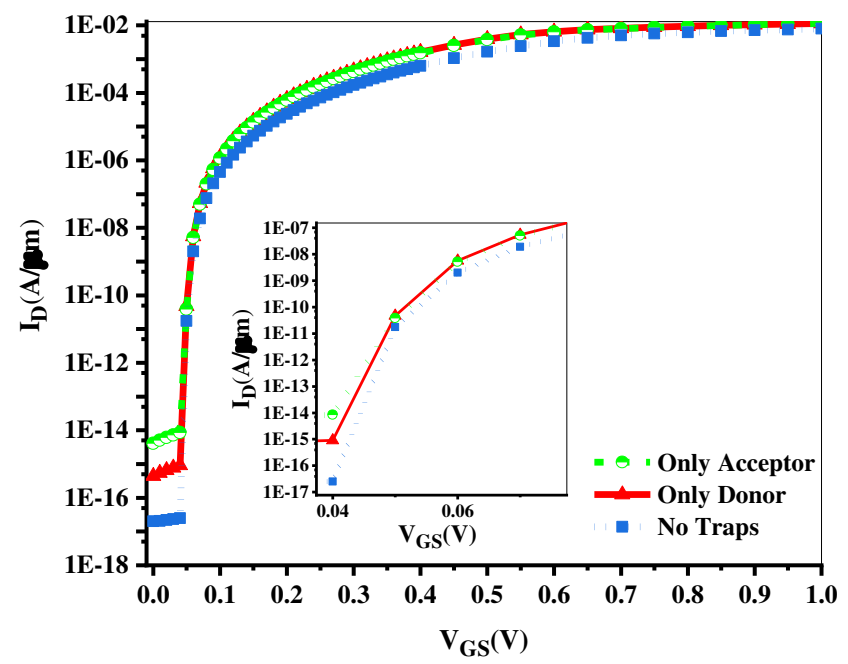

Fig. 10 The $I_{D}-V_{G S}$ characteristic in the presence of the defect in the source/channel interface. defect in the source/channel interface has negligible effects on the ON-state current, however, the OFF-state current has been affected noticeably by considering defect. 
inverse impact on $\tau$. As a result, $\mathrm{I}_{\mathrm{ON}}$ and $\mathrm{C}_{\mathrm{gg}}$ are in competition to determine $\tau$. The results in Table 1 show, in determination of $\tau$, IoN degradation overcome $\mathrm{Cgg}$ degradation. Consequently, as $\mathrm{W}_{\mathrm{SiO} 2}$ increases, $\tau$ is increased.

It should be noted that an increase in $\mathrm{W}_{\mathrm{SiO} 2}$ to values larger than $2 \mathrm{~nm}$ might be a feasible way of bringing up the breakdown voltage of oxide between $\mathrm{CG}$ and $\mathrm{PG}$; but the device performance is degraded. $\mathrm{W}_{\mathrm{SiO} 2}$ degradation to values smaller than $2 \mathrm{~nm}$ might lead to oxide breakdown between $\mathrm{CG}$ and PG. As a result, $\mathrm{W}_{\mathrm{SiO} 2}$ is considered to be $2 \mathrm{~nm}$ in our simulations.

\subsection{Impact of Band-Tails on the subthreshold behavior of $\mathbf{G a} 0.8 \mathrm{In}{ }_{0.2} \mathrm{As} / \mathbf{G a}_{0.85} \mathbf{I n}_{0.15} \mathrm{Sb}$ VHJLTFT}

Our simulation results show that band tailing due to defect in the source/channel interface is thus of importance on subthreshold performance in the proposed structure. Defects in the GaInAs/GaInSb interface can be of the donor or acceptor type, and their density may vary between $10^{5}-10^{7} \mathrm{~cm}^{-2}[34,35]$. In this section, to investigate the effect of defect in the source/channel interface on the performance of $\mathrm{Ga}{ }_{0.8} \mathrm{In}_{0.2} \mathrm{As} / \mathrm{Ga}_{0.85} \mathrm{In}_{0.15} \mathrm{Sb}$ VHJLTFT, the donor type defect density is $10^{6} \mathrm{~cm}^{-2}$ and the acceptor type defect density is $10^{7} \mathrm{~cm}^{-2}$. Figure 10 shows the $\mathrm{I}_{\mathrm{D}}-\mathrm{V}_{\mathrm{GS}}$ characteristic of the simulated devices. It can be seen that the interface defects increase the OFF-State current, followed by an increase in the subthreshold slope, see inset of Fig. 10. The OFF-state current and average SS for the proposed structure with only acceptor type defect are $4.17 \mathrm{E}-15(\mathrm{~A} / \mu \mathrm{m})$ and $4.9 \mathrm{mV} / \mathrm{dec}$ respectively, and the same parameters for the proposed structure with only donor type defect are $4.45 \mathrm{E}-16(\mathrm{~A} / \mu \mathrm{m})$ and $4.3 \mathrm{mV} / \mathrm{dec}$. Comparing the result of the simulated device without defect with the simulated device with only acceptor type defect and only donor type defect shows the increasing by $36 \%$ and $20 \%$ in the average SS.

Figure 11(a) shows the square root of the product of the electron-hole density (np) $)^{1 / 2}$ taken vertically across the tunneling junction of simulated devices in the OFF-state. As shown, (np $)^{1 / 2}$ by taking defects into account in the source/channel interface is higher than the $(\mathrm{np})^{1 / 2}$ when the defect is absent. Figure $11 \mathrm{~b}$ compares the recombination rate taken vertically across the tunneling junction of simulated devices in the OFF-state. As can be seen, the defects have shifted the maximum recombination rate to the source/channel interface. Moreover, the maximum recombination rate by taking defects into account is higher than the maximum recombination rate when the defect is absent. In fact, the defects increase the product of the electron-hole density in source/channel interface, followed by
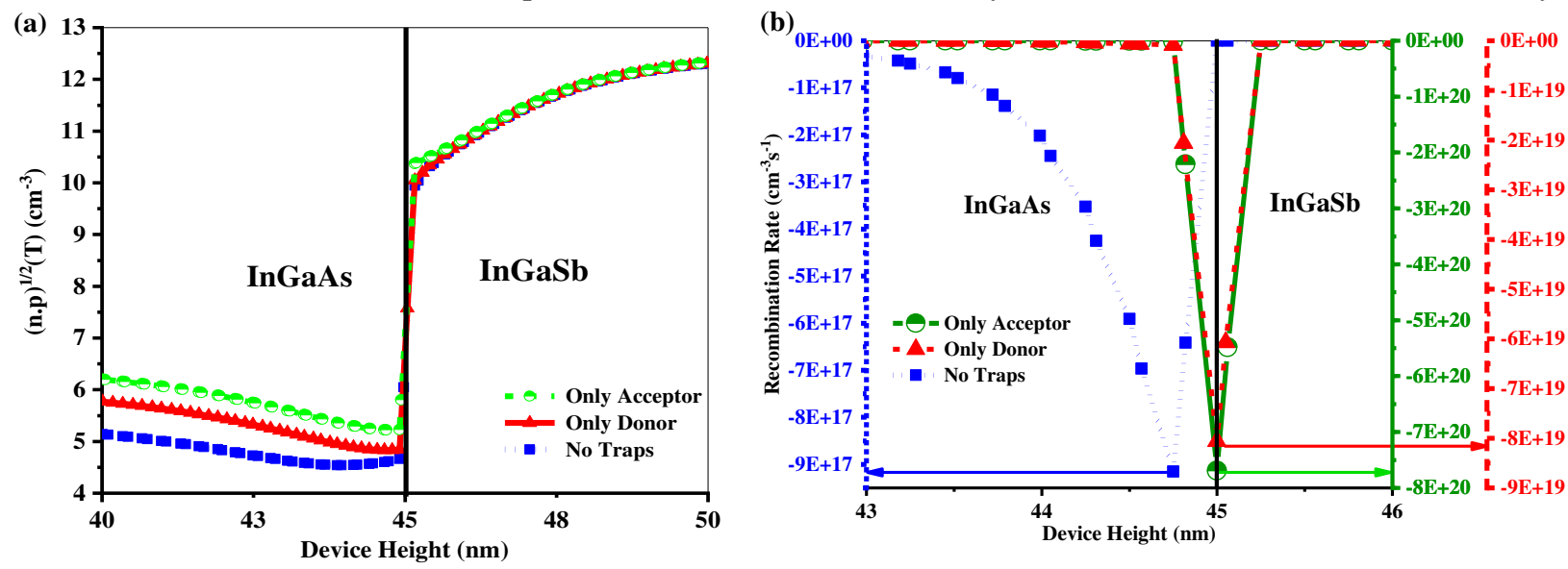

Fig.11 (a) Square product of electron-hole density and (b) recombination rate, taken vertically at the vicinity of the tunneling junction of the simulated structures in the OFF-state. The bias conditions are as follows: VGS $=0 \mathrm{~V}$ and VDS $=1 \mathrm{~V}$.

an increase in the recombination rate. As a result, the OFF-state current by taking defects into account is higher than the OFF-state current when the defect is absent. The higher $\mathrm{I}_{\mathrm{OFF}}$ due to defect results in the deteriorating the subthreshold behavior of simulated devices. 


\subsection{Sensitivity analysis}

The simulation results in this section have been presented without taking the defect of the source/channel interface into account. To obtain the sensitivity of the main electrical parameters of the $\mathrm{Ga}_{0.8} \mathrm{In}_{0.2} \mathrm{As} / \mathrm{Ga}_{0.85} \mathrm{In}_{0.15} \mathrm{Sb}$ VHJLTFET to structural parameters, such as $\mathrm{T}_{\mathrm{b}}, \mathrm{N}_{\mathrm{D}}$ and $\mathrm{W}_{\mathrm{SiO} 2}$, the sensitivity analysis is conducted. We considered $\mathrm{I}_{\mathrm{ON}}$, $\mathrm{I}_{\mathrm{OFF}}, \mathrm{I}_{\mathrm{ON}} / \mathrm{I}_{\mathrm{OFF}}$ ratio, threshold voltage $\left(\mathrm{V}_{\mathrm{th}}\right)$, and average $\mathrm{SS}$ as the main electrical parameters of VHJL-TFET. In this study, sensitivity is considered as standard deviation divided by mean. In calculating the sensitivity of a main electrical parameter to a given structural parameter, other structural parameters are considered constant. Figure 12 shows the sensitivity of main electrical parameters of $\mathrm{Ga}_{0.8} \mathrm{In}_{0.2} \mathrm{As} / \mathrm{Ga}_{0.85} \mathrm{In}_{0.15} \mathrm{Sb}$ VHJL-TFET with respect to the structural parameters. To calculate the sensitivity of the main electrical parameters with respect to $\mathrm{N}_{\mathrm{D}}$, it is assumed that $\mathrm{T}_{\mathrm{b}}=5 \mathrm{~nm}$ and $\mathrm{W}_{\mathrm{SiO} 2}=2 \mathrm{~nm}$, and $\mathrm{N}_{\mathrm{D}}$ is varied from $5 \mathrm{e} 17$ to $1 \mathrm{e} 19$. The $\mathrm{I}_{\mathrm{OFF}}$ of the simulated device has higher sensitivity than other main electrical parameters with respect to the $N_{D}$ (see Fig. 12). As $N_{D}$ increases, the channel resistance decreases and, then, the $\mathrm{I}_{\mathrm{OFF}}$ is increased.

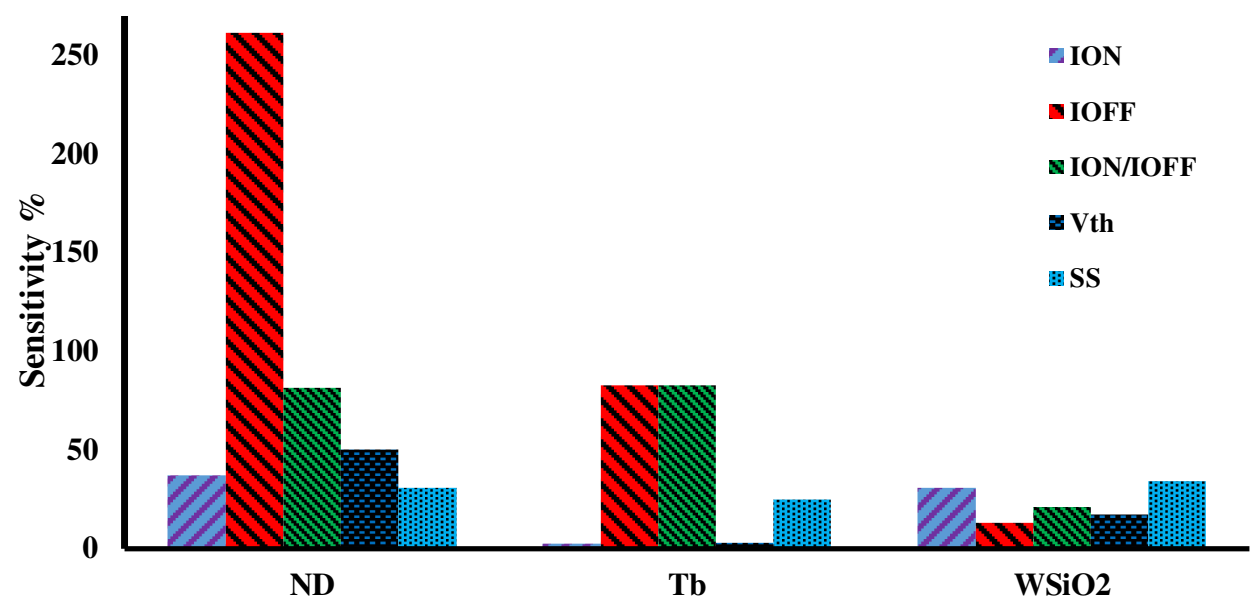

Fig.12 Sensitivity of main electrical parameters with respect to $\mathrm{N}_{\mathrm{D}}, \mathrm{T}_{\mathrm{b}}$, and $\mathrm{W}_{\mathrm{SiO} 2}$.

To calculate the sensitivity of the main electrical parameters with respect to $T_{b}, N_{D}=1 \mathrm{e} 18$ and $W_{S i O 2}=2 n m$ are assumed and $T_{b}$ is varied from $5 \mathrm{~nm}$ to $10 \mathrm{~nm}$. Figure 12 shows that $I_{O F F}$ has higher sensitivity to $T_{b}$ than other main electrical parameters. The simulation results show, with an increase in $T_{b}$, the CG control over channel is decreased and, then, the $\mathrm{I}_{\mathrm{OFF}}$ increases.

To calculate the sensitivity of the main electrical parameters with respect to $\mathrm{W}_{\mathrm{SiO} 2}, \mathrm{~N}_{\mathrm{D}}=1 \mathrm{e} 18$ and $\mathrm{T}_{\mathrm{b}}=5 \mathrm{~nm}$ are assumed and $\mathrm{W}_{\mathrm{SiO} 2}$ varies from $2 \mathrm{~nm}$ to $8 \mathrm{~nm}$. As $\mathrm{W}_{\mathrm{SiO} 2}$ increases, slope of the energy band diagram in the source/channel interface is reduced and, then, ION is reduced. As seen in Fig. 9, IoN has higher sensitivity to $\mathrm{W}_{\mathrm{SiO} 2}$ than other main electrical parameters.

Performance of $\mathrm{Ga}_{0.8} \mathrm{In}_{0.2} \mathrm{As} / \mathrm{Ga}_{0.85} \mathrm{In}_{0.15} \mathrm{Sb}$ VHJL-TFET shown in Fig. 1 is compared with the performance of the recently proposed devices in Table 2. Dual material gate heterostructure junctionless TFET (DMGE-HJLTFET) proposed in [18] has a hetero structure of $\mathrm{GaAs}_{0.1} \mathrm{Sb}_{0.9} / \mathrm{InAs}$. Oxide pocket hetero-gate-dielectric heterostructure. JLTFET (OP-HD-HS-JLTFET) proposed in [21] has a hetero structure of Si/GaSb. Heterostructure junctionless TFET (HJL-TFET) proposed in [22] has a hetero structure of GaAs/GaSb. The devices in Table 2 that are selected for comparison with the VHJL-TFET structure have a $20 \mathrm{~nm}$ channel length and $5 \mathrm{~nm}$ body thickness; the results expressed for them are extracted from [18, 21, 22]. Table 2 shows that $\mathrm{Ga}_{0.8} \mathrm{In}_{0.2} \mathrm{As}_{\mathrm{s}} / \mathrm{Ga}_{0.85} \mathrm{In}_{0.15} \mathrm{Sb}$ VHJL-TFET structure proposed in this paper with the channel length of $20 \mathrm{~nm}$ and body thickness of $5 \mathrm{~nm}$ has higher $\mathrm{I}_{\mathrm{ON}} / \mathrm{I}_{\mathrm{OFF}}$ ratio than the structures reported in $[18,21,22]$. Moreover, average SS of $\mathrm{Ga}_{0.8} \mathrm{In}_{0.2} \mathrm{As} / \mathrm{Ga}_{0.85} \mathrm{In}_{0.15} \mathrm{Sb}$ VHJL-TFET in 
comparison with DMGE-HJLTFET, OP-HD-HS-JLTFET, and HJLTFET is improved by $71 \%$, 77\%, and 66\%, respectively. As a result, the switching rate from $\mathrm{I}_{\text {OFF }}$ to $\mathrm{I}_{\mathrm{ON}}$ of $\mathrm{Ga}_{0.8} \mathrm{In}_{0.2} \mathrm{As} / \mathrm{Ga}_{0.85} \mathrm{In}_{0.15} \mathrm{Sb}$ VHJL-TFET is higher than that of the structures reported in $[18,21,22]$. The results in Table 2 show the IoN of $\mathrm{Ga}_{0.8} \mathrm{In}_{0.2} \mathrm{As} / \mathrm{Ga}_{0.85} \mathrm{In}_{0.15} \mathrm{Sb}$ VHJL-TFET is improved by $204 \%$ compared to HJL-TFET and improved by at least one order of magnitude compared to structures OP-HD-HS-JLTFET and DMGE-HJLTFET. Threshold voltage of $\mathrm{Ga}_{0.8} \mathrm{In}_{0.2} \mathrm{As} / \mathrm{Ga}_{0.85} \mathrm{In}_{0.15} \mathrm{Sb}$ VHJL-TFET compared to OP-HD-HS-JLTFET and HJL-TFET is reduced by $76 \%$ and $64 \%$, respectively (see Table 2). As a result, $\mathrm{Ga}_{0.8} \mathrm{In}_{0.2} \mathrm{As} / \mathrm{Ga}_{0.85} \mathrm{In}_{0.15} \mathrm{Sb}$ VHJL-TFET has turned on with a smaller gate voltage in comparison with OP-HD-HS-JLTFET and HJL-TFET devices. It's necessary to say for the faire comparison all parameters are compared in the absence of $\mathrm{Ga}_{0.8} \mathrm{In}_{0.2} \mathrm{As} / \mathrm{Ga}_{0.85} \mathrm{In}_{0.15} \mathrm{Sb}$ interface defects.

Table 2 Switching behavior comparison between the Ga0.8 $\operatorname{In}_{0.2} \mathrm{As} / \mathrm{Ga} 0.85 \operatorname{In}_{0.15} \mathrm{Sb}$ VHJL-TFET and the recently proposed devices $[18,21,22]$.

\begin{tabular}{cccccc}
\hline Designes & Ion $(\mathrm{A} / \mu \mathrm{m})$ & Ioff $(\mathrm{A} / \mu \mathrm{m})$ & IoN $_{\text {IOFF }}$ & $\mathrm{SS}(\mathrm{mV} / \mathrm{dec})$ & $\mathrm{V}_{\text {th }}(\mathrm{V})$ \\
\hline DMGE-HJLTFET [18] & $5.46 \mathrm{E}-04$ & $8.40 \mathrm{E}-18$ & $6.50 \mathrm{E}+13$ & 15.4 & $\cdots$ \\
OP-HD-HS-JLTFET [21] & $4.69 \mathrm{E}-4$ & $5.419 \mathrm{E}-17$ & $8.66 \mathrm{E}+12$ & 19 & 0.33 \\
HJL-TFET [22] & $2.63 \mathrm{E}-03$ & $3.548 \mathrm{E}-17$ & $7.4 \mathrm{E}+13$ & 13 & 0.22 \\
VHJL-TFET & $\mathbf{8 . 0 0 E - 0 3}$ & $2.00 \mathrm{E}-17$ & $4.00 \mathrm{E}+14$ & 4.4 & 0.08 \\
\hline
\end{tabular}

Due to the tunneling mechanism, the $\mathrm{I}_{\mathrm{ON}}$ of TFET is less than devices in which the current mechanism is thermionic emission. This is the main restriction of the TFET device. $\mathrm{I}_{\mathrm{ON}}$ of $\mathrm{Ga}_{0.8} \mathrm{In}_{0.2} \mathrm{As} / \mathrm{Ga}_{0.85} \mathrm{In}_{0.15} \mathrm{Sb}$ VHJL-TFET proposed in this paper is compared with the devices, in which the current mechanism is thermionic emission. Nanotube junctionless FET (NJLFET) proposed in [36] with 30nm gate length has $\mathrm{I}_{\mathrm{ON}}=24.9 \mu \mathrm{A}$. Junctionless field effect diode (JL-FED) proposed in [28] with a $30 \mathrm{~nm}$ channel length has $\mathrm{I}_{\mathrm{ON}}=0.1 \mathrm{~mA} / \mu \mathrm{m}$. Our simulation results show that $\mathrm{Ga}_{0.8} \mathrm{In}_{0.2} \mathrm{As} / \mathrm{Ga}_{0.85} \mathrm{In}_{0.15} \mathrm{Sb}$ VHJL-TFET proposed here with a $30 \mathrm{~nm}$ channel length has $\mathrm{I}_{\mathrm{ON}}=8 \mathrm{~mA} / \mu \mathrm{m}$. The $\mathrm{I}_{\mathrm{ON}}$ $\mathrm{Ga}_{0.8} \mathrm{In}_{0.2} \mathrm{As} / \mathrm{Ga}_{0.85} \mathrm{In}_{0.15} \mathrm{Sb}$ VHJL-TFET is higher than that of the recently proposed devices [28, 36]. Consequently, there is no low IoN restriction in proposed $\mathrm{Ga}_{0.8} \mathrm{In}_{0.2} \mathrm{As} / \mathrm{Ga}_{0.85} \mathrm{In}_{0.15} \mathrm{Sb}$ VHJL-TFET device.

\section{Conclusion}

In this paper, the effects of changes in indium mole fraction $(\mathrm{X})$ in the drain-channel region and $\mathrm{Y}$ in the source region are comprehensively examined by numerical simulator to improve digital benchmarking parameters of $\mathrm{Gax}_{\mathrm{X}} \mathrm{In}_{1-\mathrm{X}} \mathrm{As} / \mathrm{Gay}_{\mathrm{Y}} \mathrm{In}_{1-\mathrm{Y}} \mathrm{Sb}$ VHJL-TFET. With changes in X and Y, type I, type II and type III hetero structures are formed in the source/channel interface. For $\mathrm{Ga}_{0.8} \mathrm{In}_{0.2} \mathrm{As} / \mathrm{Ga}_{0.85} \mathrm{In}_{0.15} \mathrm{Sb}$ VHJL-TFET (type II hetero structure), there is a small overlap between source valence band and channel conduction band in OFF-state. Additionally, electron and hole tunneling effective mass is increased. Thus, IOFF is decreased significantly. Simulation results for $\mathrm{Ga}_{0.8} \mathrm{In}_{0.2} \mathrm{As} / \mathrm{Ga}_{0.85} \mathrm{In}_{0.15} \mathrm{Sb}$ VHJL-TFET in ON-state showed that electron and hole tunneling effective mass is compensated for by reducing tunneling barrier width. Moreover, in the proposed device, III-V semiconductors are used throughout the device. As a result, $\mathrm{I}_{\mathrm{ON}}$ of $\mathrm{Ga}_{0.8} \mathrm{In}_{0.2} \mathrm{As} / \mathrm{Ga}_{0.85} \mathrm{In}_{0.15} \mathrm{Sb}$ VHJL-TFET is reasonable, which meet the requirements of international technology roadmap for semiconductors. $\mathrm{Ga}_{0.8} \mathrm{In}_{0.2} \mathrm{As} / \mathrm{Ga}_{0.85} \mathrm{In}_{0.15} \mathrm{Sb}$ VHJL-TFET with a $20 \mathrm{~nm}$ channel length has $\mathrm{I}_{\mathrm{ON}} / \mathrm{I}_{\mathrm{OFF}}=4 \mathrm{E} 14$ and $\mathrm{SS}=4.4 \mathrm{mV} / \mathrm{dec}$ and could be a good candidate for digital applications. Also, in the proposed device, we has $\mathrm{I}_{\mathrm{ON}}=8 \mathrm{~mA} / \mathrm{um}$ and maximum transconductance is $19 \mathrm{mS} / \mathrm{um}$. As a result, the proposed device could be reasonable for analog applications.

Changes in structural parameters on the performance of $\mathrm{Ga}_{0.8} \mathrm{In}_{0.2} \mathrm{As} / \mathrm{Ga}_{0.85} \mathrm{In}_{0.15} \mathrm{Sb}$ VHJL-TFET are examined. Our simulation results show that, with an increase in doping concentration in the proposed device, the CG control over 
the channel decreases; therefore, $\mathrm{I}_{\mathrm{OFF}}$ is increased. Also, as $\mathrm{W}_{\mathrm{SiO} 2}$ increases, the slope of the energy band diagram decreases in source/channel interface and the $\mathrm{I}_{\mathrm{ON}}$ is reduced. As a result, $\mathrm{T}$ is raised by increasing $\mathrm{W}_{\mathrm{SiO} 2}$. The results represented that the I IFF has higher sensitivity to doping concentration and body thickness than other main electrical parameters. Furthermore, the sensitivity of $\mathrm{I}_{\mathrm{ON}}$ to $\mathrm{W}_{\mathrm{SiO} 2}$ is higher than that of $\mathrm{I}_{\mathrm{OFF}}$ to $\mathrm{W}_{\mathrm{SiO} 2}$.

All the results reported in this study are regardless of the effects of defects in interfacial regions of $\mathrm{Ga}_{X} \mathrm{In}_{1}$ $\mathrm{xAs} / \mathrm{Ga}_{\mathrm{Y} I n}{ }_{1-\mathrm{YSb}} \mathrm{Sb}$ layers. For more accurate results, minor improvements can be applied for considering defects in the simulation.

\section{References}

1. Asra, R., Shrivastava, M., Murali, K. V., Pandey, R. K., Gossner, H., \& Rao, V. R. (2011). A tunnel FET for $\mathrm{V}_{\mathrm{DD}}$ scaling below $0.6 \mathrm{~V}$ with a CMOS-comparable performance. IEEE Transactions on Electron Devices, 58(7), 1855-1863.

2. Morris, D. H., Avci, U. E., Rios, R., \& Young, I. A. (2014). Design of low voltage tunneling-FET logic circuits considering asymmetric conduction characteristics. IEEE Journal on Emerging and Selected Topics in Circuits and Systems, 4(4), 380-388.

3. Shih, C. H., \& Chien, N. D. (2011). Sub-10-nm tunnel field-effect transistor with graded Si/Ge heterojunction. IEEE Electron Device Letters, 32(11), 1498-1500.

4. Shih, C. H., \& Dang Chien, N. (2013). Physical operation and device design of short-channel tunnel fieldeffect transistors with graded silicon-germanium heterojunctions. Journal of Applied Physics, 113(13), 134507.

5. Li, C., Zhao, X., Zhuang, Y., Yan, Z., Guo, J., \& Han, R. (2018). Optimization of L-shaped tunneling fieldeffect transistor for ambipolar current suppression and Analog/RF performance enhancement. Superlattices and Microstructures, 115, 154-167.

6. Ghosh, B., \& Akram, M. W. (2013). Junctionless tunnel field effect transistor. IEEE electron device letters, 34(5), 584-586.

7. Ghosh, B., Bal, P., \& Mondal, P. (2013). A junctionless tunnel field effect transistor with low subthreshold slope. Journal of Computational Electronics, 12(3), 428-436.

8. Basak, S., Asthana, P. K., Goswami, Y., \& Ghosh, B. (2015). Leakage current reduction in junctionless tunnel FET using a lightly doped source. Applied Physics A, 118(4), 1527-1533.

9. Abadi, R. M. I., \& Ziabari, S. A. S. (2016). Improved performance of nanoscale junctionless tunnel fieldeffect transistor based on gate engineering approach. Applied Physics A, 122(11), 1-9.

10. Tirkey, S., Sharma, D., Yadav, D. S., \& Yadav, S. (2017). Analysis of a novel metal implant junctionless tunnel FET for better DC and analog/RF electrostatic parameters. IEEE Transactions on Electron Devices, 64(9), 3943-3950.

11. Rahimian, M., \& Fathipour, M. (2017). Improvement of electrical performance in junctionless nanowire TFET using hetero-gate-dielectric. Materials Science in Semiconductor Processing, 63, 142-152.

12. Ahangari, Z. (2018). Performance investigation of a semi-junctionless type II heterojunction tunnel field effect transistor in nanoscale regime. Micro \& Nano Letters, 13(8), 1165-1169.

13. Biswal, S. M., Swain, S. K., Sahoo, J. R., Swain, A. K., Routaray, K., Nanda, U., \& Biswal, B. (2019). A Comparative Study of Junctionless Triple-Material Cylindrical Surrounding Gate Tunnel FET. In Microelectronics, Electromagnetics and Telecommunications (pp. 793-801). Springer, Singapore.

14. Anghel, C., Chilagani, P., Amara, A., \& Vladimirescu, A. (2010). Tunnel field effect transistor with increased ON current, low-k spacer and high-k dielectric. applied physics letters, 96(12), 122104. 
15. Pown, M., \& Lakshmi, B. (2016). Investigation of $\mathrm{ft}$ and fmax in Si and Si1-xGex based single and dual material double-gate Tunnel FETs for RF applications. Advances in Natural Sciences: Nanoscience and Nanotechnology, 7(2), 025006.

16. Kurniawan, E. D., Yang, S. Y., Thirunavukkarasu, V., \& Wu, Y. C. (2017). Analysis of Ge-Si heterojunction nanowire tunnel FET: impact of tunneling window of band-to-band tunneling model. Journal of The Electrochemical Society, 164(11), E3354.

17. Anand, S., \& Sarin, R. K. (2018). Hetero-material gate doping-less tunnel FET and its misalignment effects on analog/RF parameters. Journal of Electronic Materials, 47(5), 2988-2996.

18. Xie, H., Liu, H., Chen, S., Han, T., \& Wang, S. (2019). Design and investigation of a dual material gate arsenic alloy heterostructure junctionless TFET with a lightly doped Source. Applied Sciences, 9(19), 4104.

19. Chander, S., Singh, P., \& Baishya, S. (2013). Optimization of direct tunneling gate leakage current in ultrathin gate oxide FET with High-K dielectrics. International Journal of Recent Development in Engineering and Technology, 1(1), 24-30.

20. Abadi, R. M. I., \& Ziabari, S. A. S. (2016). Representation of type I heterostructure junctionless tunnel field effect transistor for high-performance logic application. Applied Physics A, 122(6), 1-7.

21. Abedini, M., Ziabari, S. A. S., \& Eskandarian, A. (2019). Representation of an Improved Heterostructure Junctionless Tunneling FET Based on the Drain/Gate Oxide and Hetero-Dielectric Engineering. Journal of Electronic Materials, 48(9), 5865-5874.

22. Vadizadeh, M. (2018). Characteristics of GaAs/GaSb tunnel field-effect transistors without doping junctions: numerical studies. Journal of Computational Electronics, 17(2), 745-755.

23. Asthana, P. K., Ghosh, B., Goswami, Y., \& Tripathi, B. M. M. (2014). High-speed and low-power ultradeep-submicrometer III-V heterojunctionless tunnel field-effect transistor. IEEE Transactions on Electron Devices, 61(2), 479-486.

24. Wang, H., Han, G., Liu, Y., Hu, S., Zhang, C., Zhang, J., \& Hao, Y. (2015). Theoretical investigation of performance enhancement in $\mathrm{GeSn} / \mathrm{SiGeSn}$ type-II staggered heterojunction tunneling FET. IEEE Transactions on Electron Devices, 63(1), 303-310.

25. Kim, J. H., Kim, S., \& Park, B. G. (2019). Double-gate TFET with vertical channel sandwiched by lightly doped Si. IEEE Transactions on Electron Devices, 66(4), 1656-1661.

26. Rahi, S. B., Asthana, P., \& Gupta, S. (2017). Heterogate junctionless tunnel field-effect transistor: future of low-power devices. Journal of Computational Electronics, 16(1), 30-38.

27. Shur, M. S. (1996). Handbook series on semiconductor parameters (Vol. 1). World Scientific.

28. Vadizadeh, M. (2019). Junctionless field effect diode (JL-FED): A first-principles study. ECS Journal of Solid State Science and Technology, 8(6), M60.

29. “ATLAS User's Manual (2013).” [Online]. Available: http://www.silvaco.com.

30. Vadizadeh, M. (2017). Designing a hetrostructure junctionless-field effect transistor (HJL-FET) for highspeed applications. Journal of the Korean Physical Society, 71(5), 275-282.

31. Chau, R., Datta, S., Doczy, M., Doyle, B., Jin, B., Kavalieros, J., \& Radosavljevic, M. (2005). Benchmarking nanotechnology for high-performance and low-power logic transistor applications. IEEE transactions on nanotechnology, 4(2), 153-158.

32. Boucart, K., \& Ionescu, A. M. (2007). Double-gate tunnel FET with high-א gate dielectric. IEEE transactions on electron devices, 54(7), 1725-1733.

33. Lattanzio, L., De Michielis, L., \& Ionescu, A. M. (2012). The electron-hole bilayer tunnel FET. Solid-State Electronics, 74, 85-90.

34. Jasik, A., Sankowska, I., Wawro, A., Ratajczak, J., Smoczyński, D., \& Czuba, K. (2019). GaSb layers with low defect density deposited on (001) GaAs substrate in two-dimensional growth mode using molecular beam epitaxy. Current Applied Physics, 19(4), 542-547. 
35. Baryshnikova, M., Mols, Y., Ishii, Y., Alcotte, R., Han, H., Hantschel, T., ... \& Kunert, B. (2020). NanoRidge Engineering of $\mathrm{GaSb}$ for the Integration of $\mathrm{InAs} / \mathrm{GaSb}$ Heterostructures on $300 \mathrm{~mm}(001)$ Si. Crystals, 10(4), 330.

36. Rewari, S., Nath, V., Haldar, S., Deswal, S. S., \& Gupta, R. S. (2016). Improved analog and AC performance with increased noise immunity using nanotube junctionless field effect transistor (NJLFET). Applied Physics A, 122(12), 1-10. 
(a)
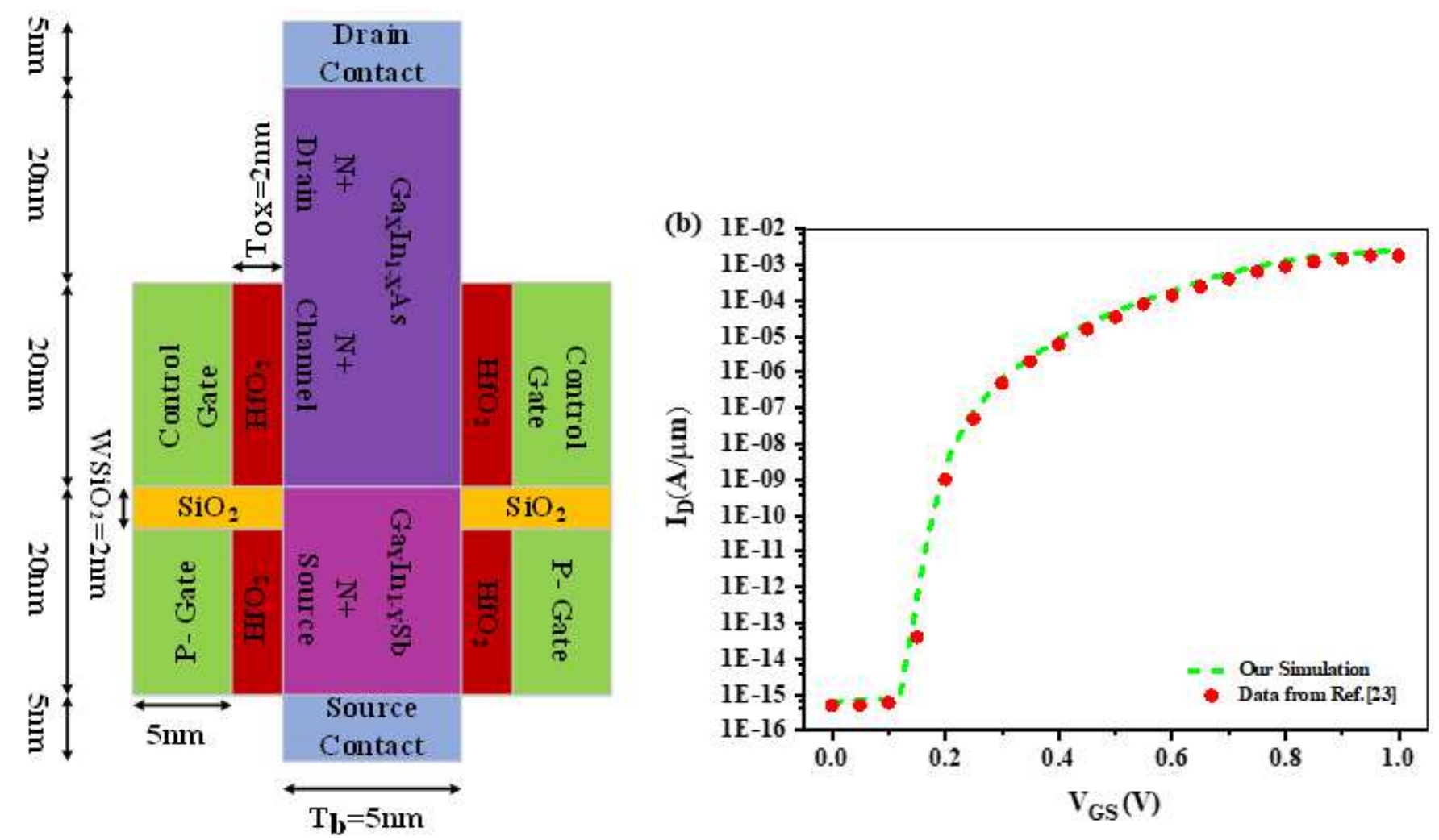

Figure 1

(a) Device structure of a GaXIn1-XAs/GaYIn1-YSb VHJL-TFET (not to scale) and (b) Calibration with the published result, ID-VGS characteristics of $20 \mathrm{~nm}$ gate length HJL-TFET reported in Ref.[23].
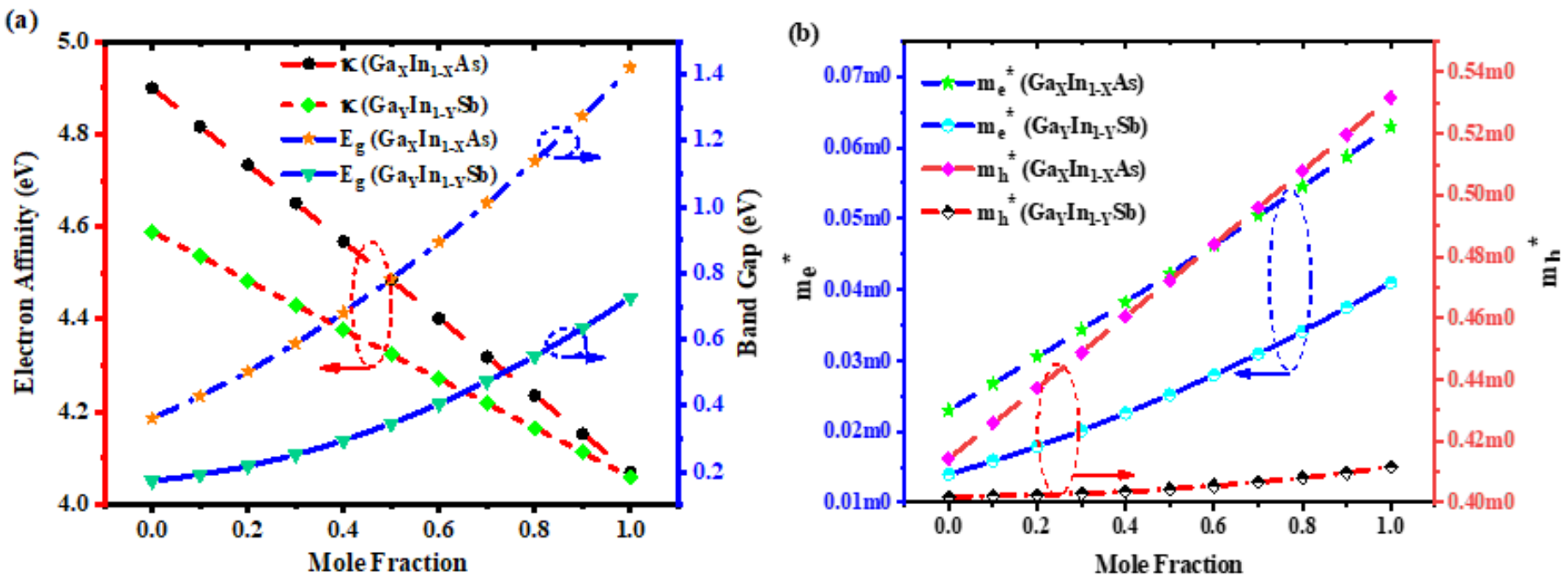

Figure 2 
(a) Energy band gap and electron affinity as a function of $X$ and $Y$ mole fractions. (b) Electron tunneling effective mass and hole tunneling effective mass as a function of $X$ and $Y$ mole fractions.
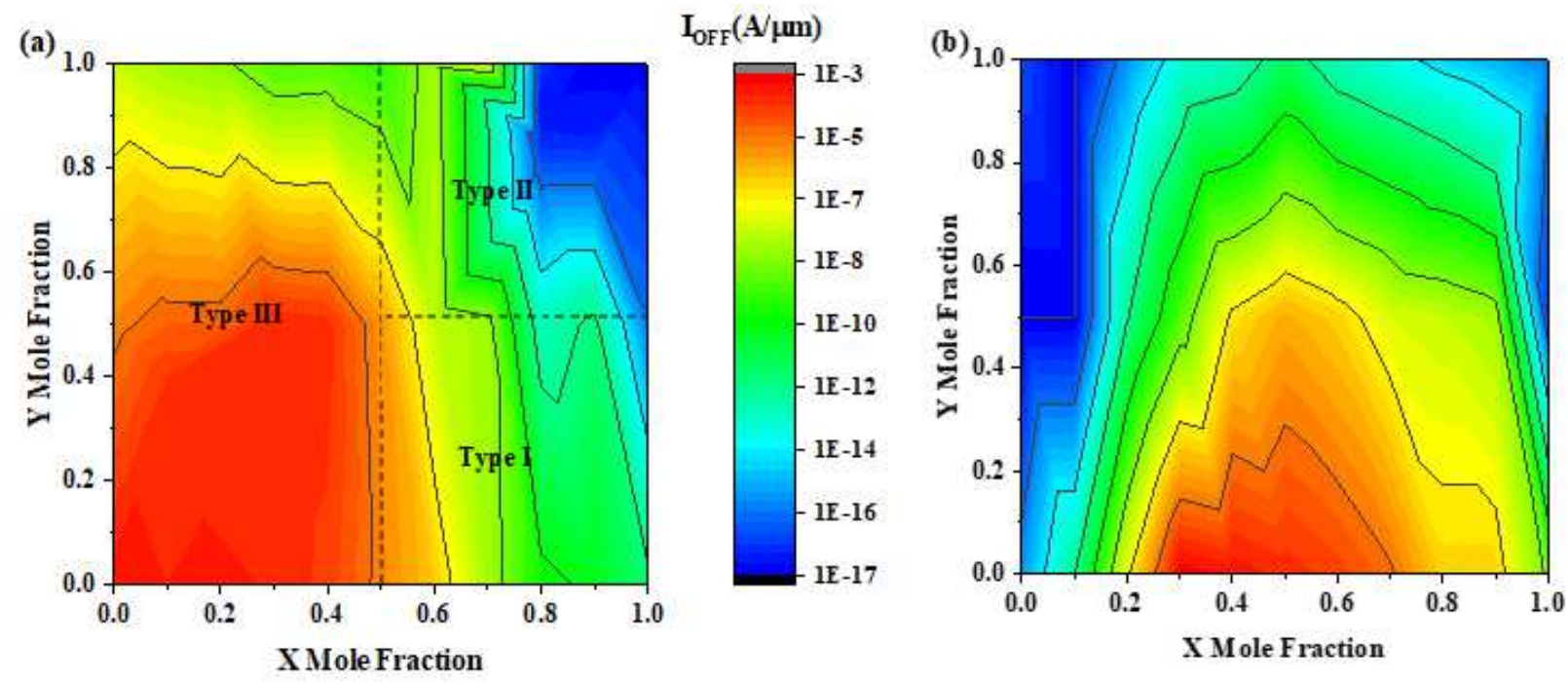

$\mathrm{I}_{\mathrm{ON}}(\mathrm{A} / \mu \mathrm{m})$

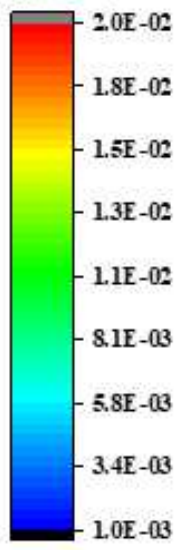

Figure 3

2D variation matrix of (a) OFF-state current (IOFF) and (b) ON-state current (ION) as a function of $X$ and $Y$ mole fractions. ION is measured at bias conditions of VGS $=1 \mathrm{~V}, \mathrm{VDS}=1 \mathrm{~V}$. IOFF is measured at bias conditions of VGS $=0 \mathrm{~V}, \mathrm{VDS}=1 \mathrm{~V}$.
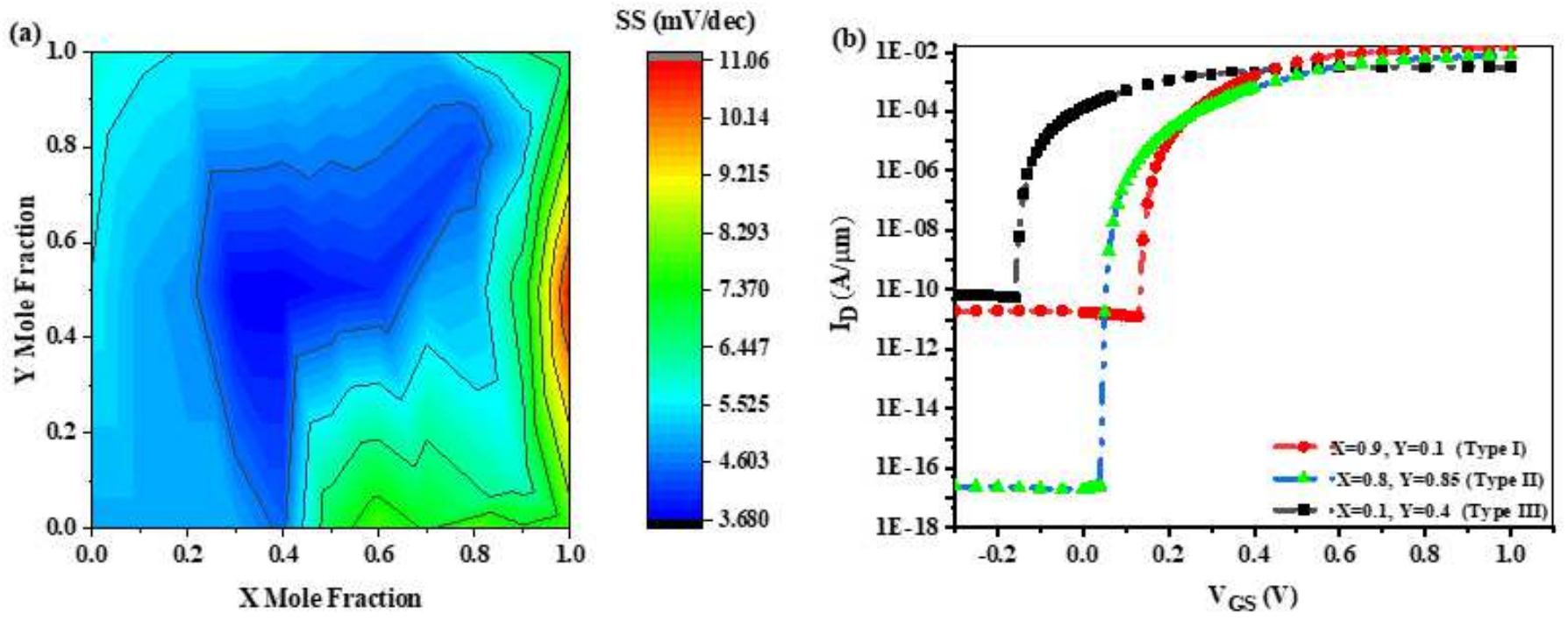

\section{Figure 4}

(a) 2D variation matrix of average subthreshold slope (SS) as a function of $X$ and $Y$ mole fractions. $1 \mathrm{~V}$. Average SS of simulated structures has been calculated based on the method discussed in [22, 32]. (b) Input characteristics of GaXIn1-XAs/GaYIn1-YSb VHJL-TFET for typel $(X=0.9, Y=0.1)$, typell $(X=0.8$, $Y=0.85)$ and typelll $(X=0.1, Y=0.4)$, the bias condition is VDS $=1 \mathrm{~V}$. 

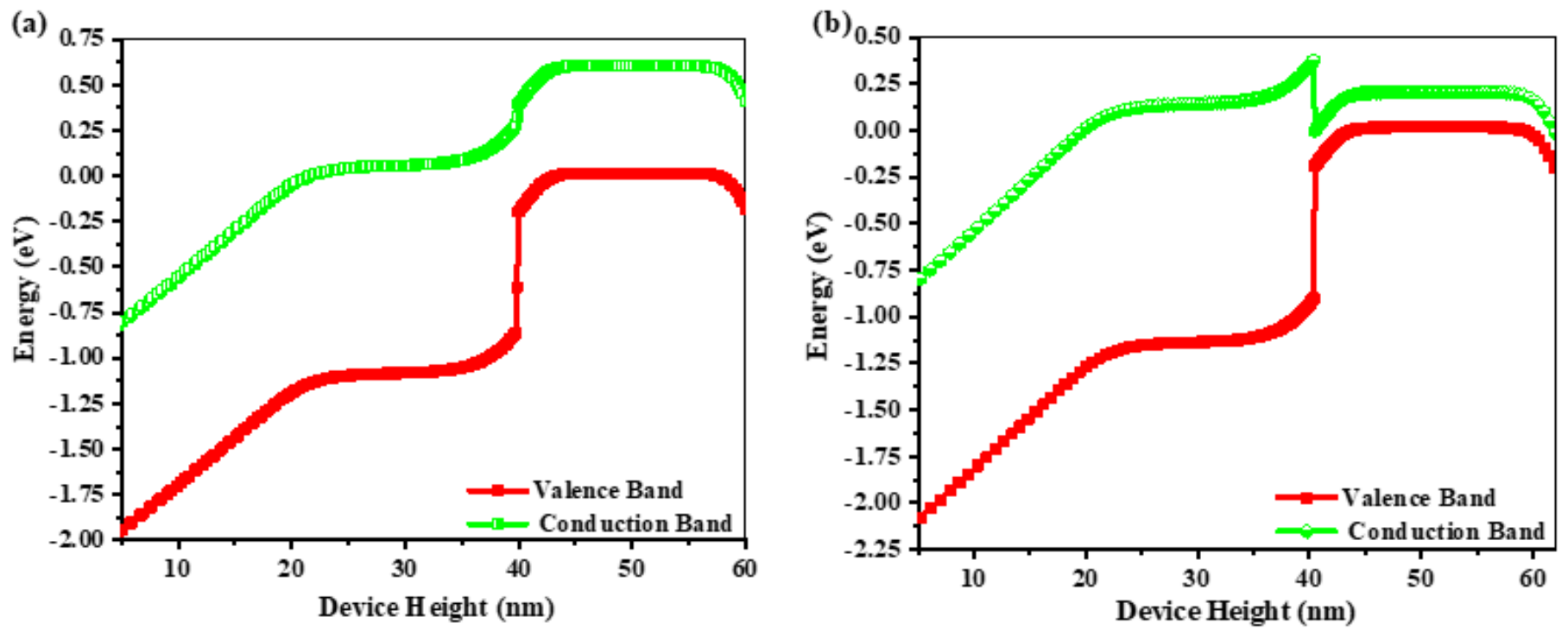

Figure 5

Energy band diagram, taken vertically across the GaXIn1-XAs/GaYIn1-YSb VHJL-TFET for (a) typell $(X=0.8, Y=0.85)$ and (b) typel $(X=0.9, Y=0.1)$. The bias conditions are as follows VGS=0V, VDS=1V.

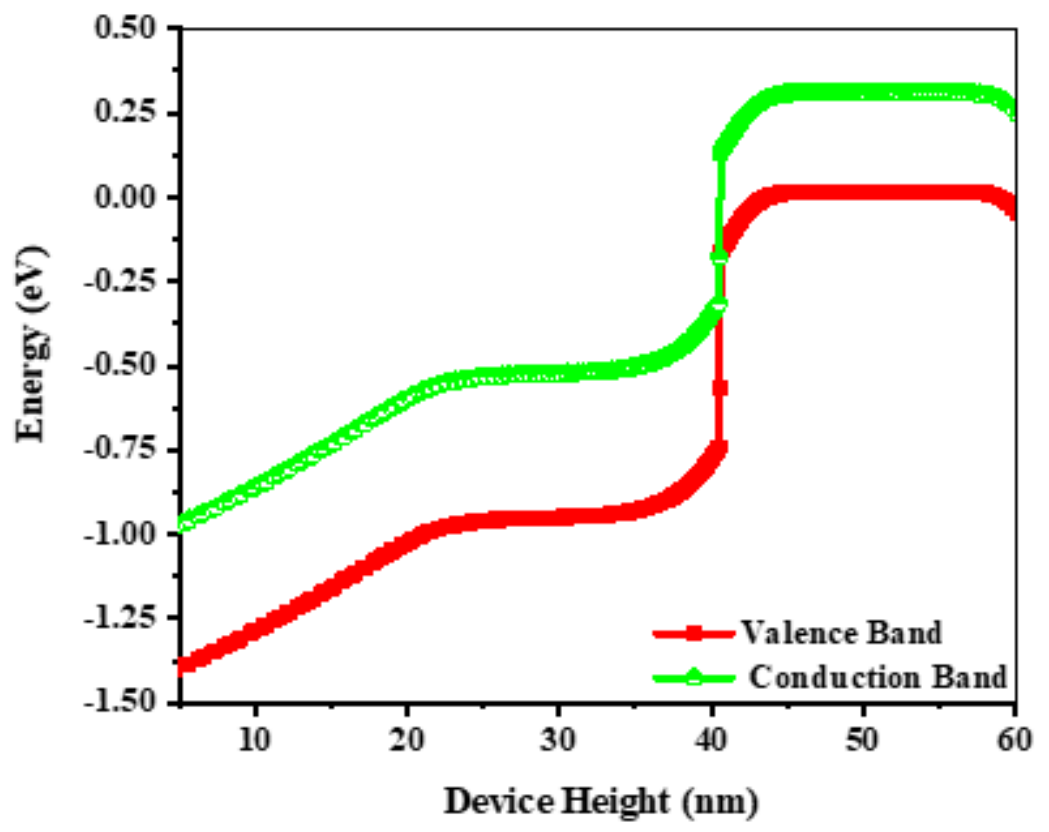

Figure 6

Energy band diagram, taken vertically across the Ga0.1 In0.9As/Ga0.4In0.6Sb VHJL-TFET (i.e. typellI). 

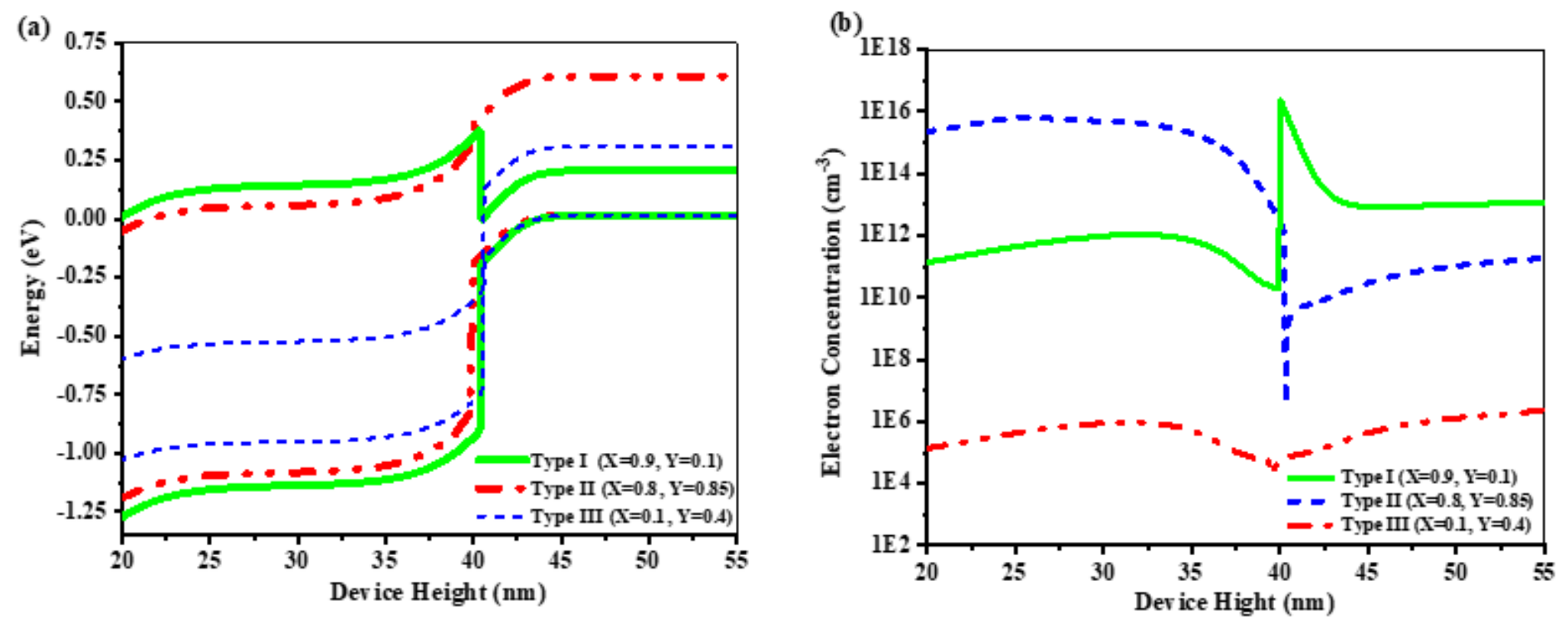

Figure 7

(a) Energy band diagram comparison and (b) electron concentration comparison between type I, type II, and type III heterostructures at the vicinity of the source/channel interface. The bias conditions are as follows VGS=0V, VDS=1V.
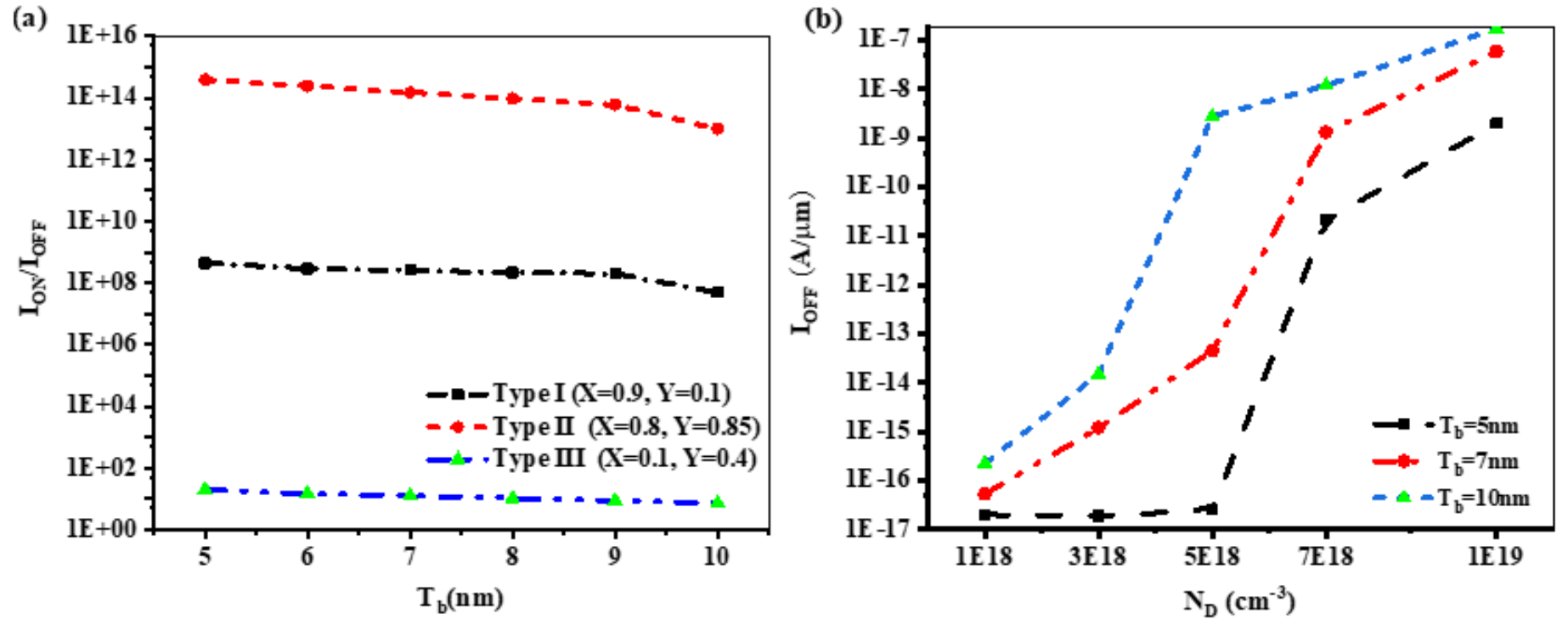

Figure 8

(a) ON/OFF current ration as a function of body thickness (Tb) of GaXIn1-XAs/GaYIn1-YSb VHJL-TFET with ND $=1 \times 1018 \mathrm{~cm}-3$ for various mole fractions. (b) IOFF as a function of doping concentration (ND) of $\mathrm{Ga} 0.8 \mathrm{In} 0.2 \mathrm{As} / \mathrm{Ga} 0.85 \mathrm{In} 0.15 \mathrm{As}$ VHJL-TFET for various body thicknesses. ION is measured at bias conditions of VGS $=1 \mathrm{~V}, \mathrm{VDS}=1 \mathrm{~V}$. IOFF is measured at bias conditions of VGS=0V, VDS $=1 \mathrm{~V}$. 

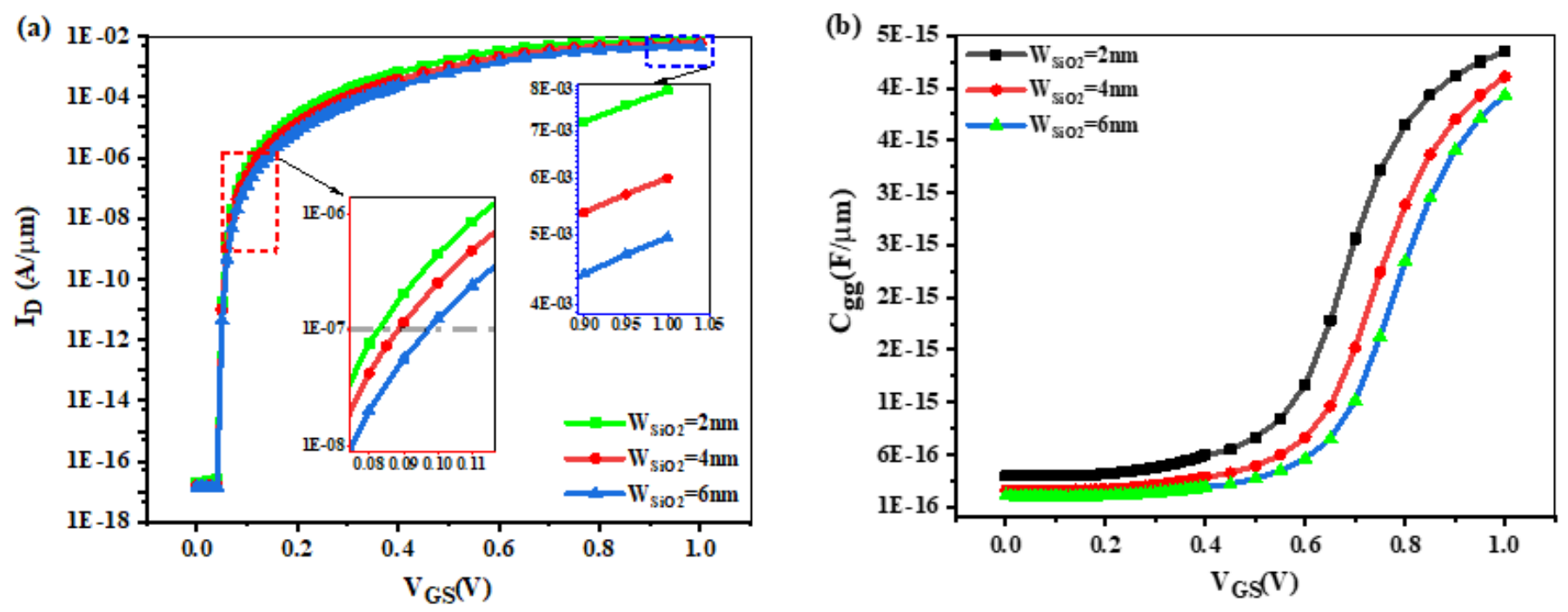

Figure 9

(a) Drain current and (b) the total gate-to-gate capacitance as a function of gate bias of $\mathrm{Ga} 0.8 \mathrm{In} 0.2 \mathrm{As} / \mathrm{Ga} 0.85 \mathrm{In} 0.15 \mathrm{As}$ VHJL-TFET for various WSiO2. The inset of Fig. 9(a) shows the ID-VGS of simulate device in above threshold region. The bias condition is VDS $=1 \mathrm{~V}$.

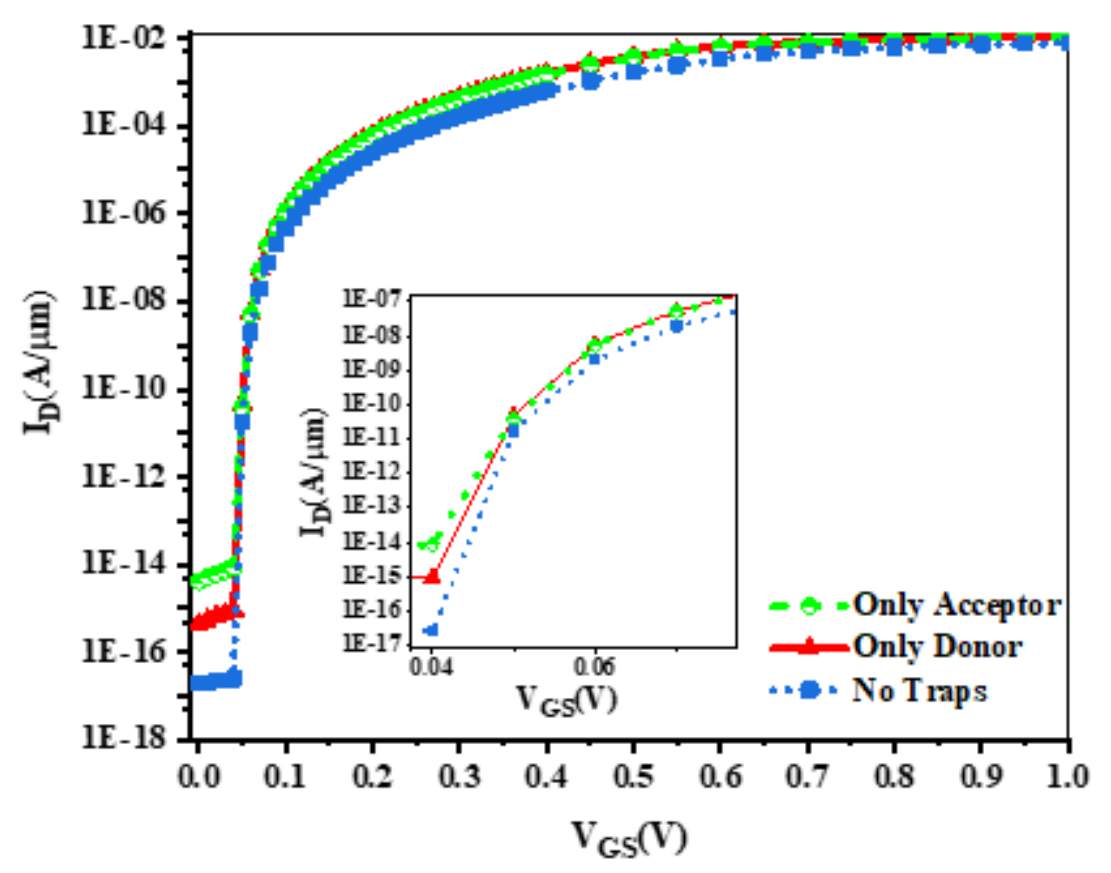

Figure 10

The ID-VGS characteristic in the presence of the defect in the source/channel interface. defect in the source/channel interface has negligible effects on the ON-state current, however, the OFF-state current has been affected noticeably by considering defect. 

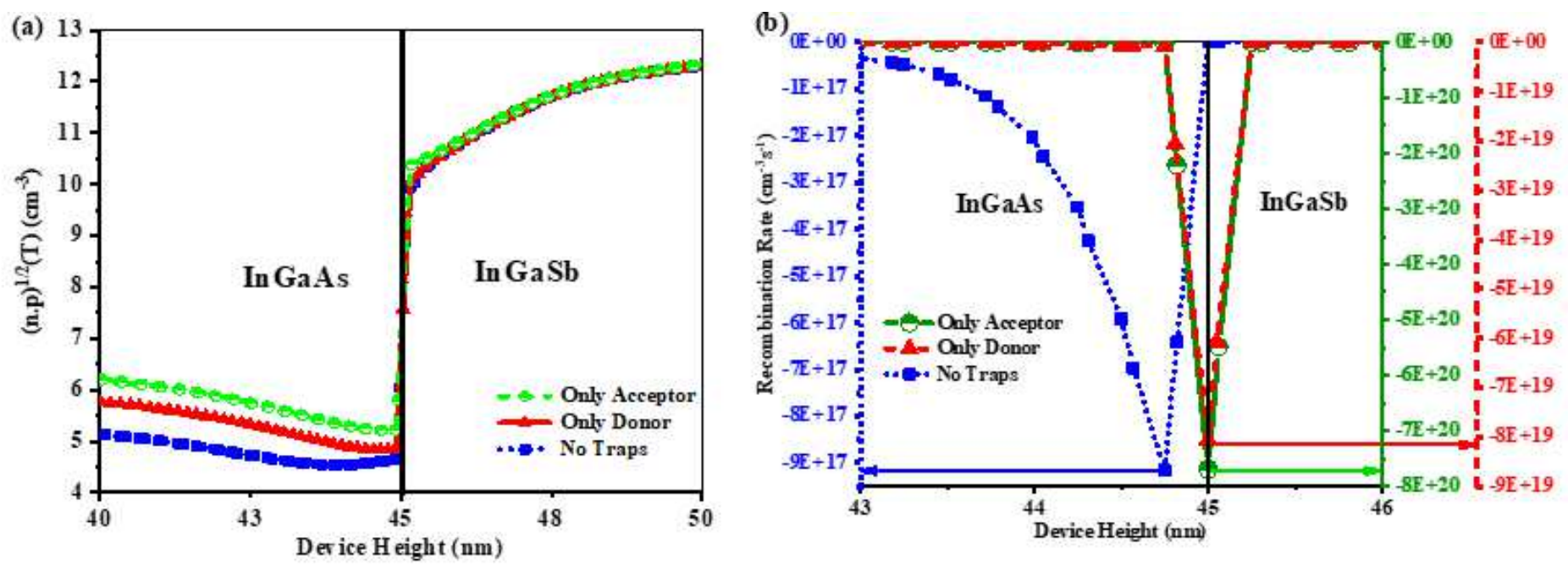

\section{Figure 11}

(a) Square product of electron-hole density and (b) recombination rate, taken vertically at the vicinity of the tunneling junction of the simulated structures in the OFF-state. The bias conditions are as follows: $\mathrm{VGS}=0 \mathrm{~V}$ and $\mathrm{VDS}=1 \mathrm{~V}$.

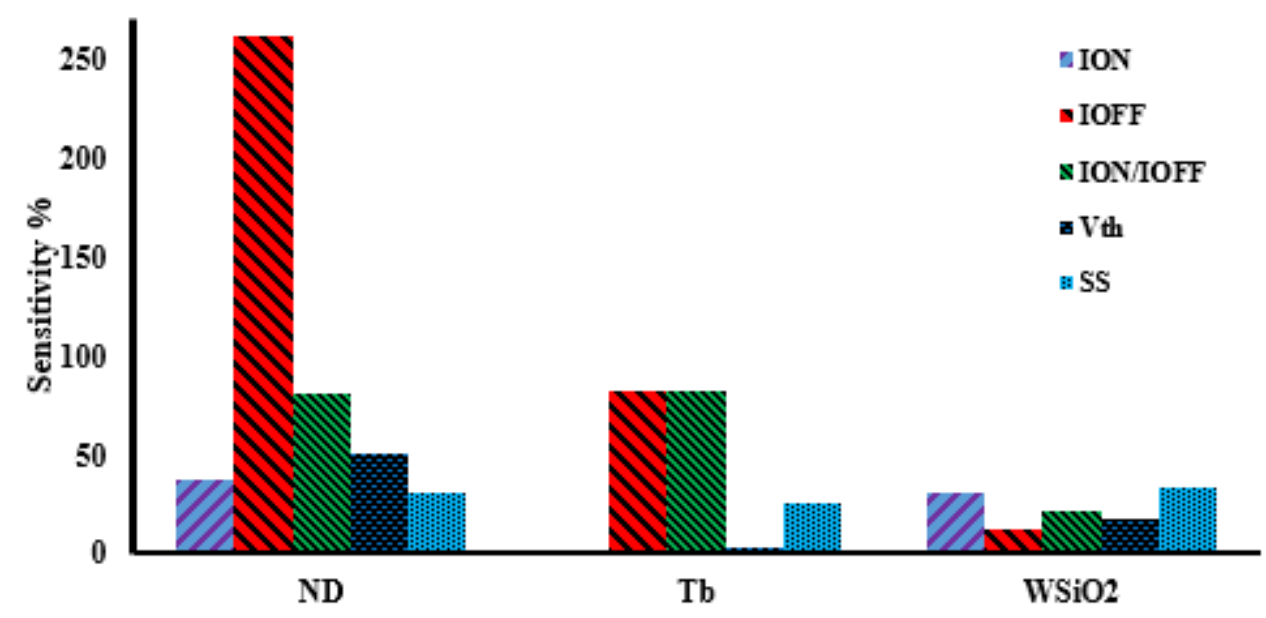

Figure 12

Sensitivity of main electrical parameters with respect to ND, Tb, and WSiO2. 